San Jose State University

SJSU ScholarWorks

Master's Theses

Master's Theses and Graduate Research

Spring 2011

\title{
The Impact of Hurricane Katrina on Gulf Coast Libraries and Their Disaster Planning
}

Jeffrey Frank

San Jose State University

Follow this and additional works at: https://scholarworks.sjsu.edu/etd_theses

\section{Recommended Citation}

Frank, Jeffrey, "The Impact of Hurricane Katrina on Gulf Coast Libraries and Their Disaster Planning" (2011). Master's Theses. 3925.

DOI: https://doi.org/10.31979/etd.wkbu-cu6k

https://scholarworks.sjsu.edu/etd_theses/3925

This Thesis is brought to you for free and open access by the Master's Theses and Graduate Research at SJSU ScholarWorks. It has been accepted for inclusion in Master's Theses by an authorized administrator of SJSU ScholarWorks. For more information, please contact scholarworks@sjsu.edu. 


\title{
THE IMPACT OF HURRICANE KATRINA ON GULF COAST LIBRARIES AND THEIR DISASTER PLANNING
}

\author{
A Thesis \\ Presented to \\ The Faculty of the School of Library and Information Science \\ San José State University \\ In Partial Fulfillment \\ of the Requirements for the Degree \\ Master of Library and Information Science \\ by \\ Jeffrey M. Frank
}

May 2011 
(C) 2011

Jeffrey M. Frank

ALL RIGHTS RESERVED 
The Designated Thesis Committee Approves the Thesis Titled

THE IMPACT OF HURRICANE KATRINA ON GULF COAST LIBRARIES AND

THEIR DISASTER PLANNING

\author{
by \\ Jeffrey M. Frank \\ APPROVED FOR THE SCHOOL OF LIBRARY AND INFORMATION SCIENCE \\ SAN JOSÉ STATE UNIVERSITY
}

May 2011

Dr. Debra L. Hansen

School of Library and Information Science

Dr. Patricia C. Franks

School of Library and Information Science

Dr. Susan Aber

Emporia State University 


\begin{abstract}
THE IMPACT OF HURRICANE KATRINA ON GULF COAST LIBRARIES AND THEIR DISASTER PLANNING

by Jeffrey M. Frank
\end{abstract}

In August 2005, Hurricane Katrina made landfall along the Gulf Coast, becoming infamous for the destruction it wrought to communities from Louisiana to Alabama. Most notably, it caused massive flooding in New Orleans and surrounding parishes by breaching the levee system. The storm's impact on the region's population, buildings, and collective psyche is impossible to measure. As was the case with other Gulf Coast institutions in the path of Hurricane Katrina, the region's libraries also suffered extensively.

Through examination of the available literature and first-hand accounts of library professionals, this thesis examines the impact that Hurricane Katrina had on libraries in southeastern Louisiana, the New Orleans metropolitan area, and Southern Mississippi. It also considers the role disaster plans played in preserving select libraries' collections as well as some of the problems occurring with their implementation during the disaster. It was discovered that library disaster plans are designed to mitigate small, localized disasters, not those on the scale of Hurricane Katrina. It was also found that large scale disasters, like a hurricane or earthquake, render such plans ineffective, though action taken by library staff before and immediately afterward can make some difference. The thesis concludes with a list of recommendations for library disaster planning in the future. 


\section{ACKNOWLEDGEMENTS}

As with any undertaking such as this, it is something not done alone. There are numerous people and entities due my heartfelt gratitude, appreciation, and thanks:

My Thesis Chair and Graduate Advisor, Dr. Debra Hansen. You have been a limitless reserve of knowledge, guidance, support, ideas, and patience during this endeavor. "Thank you" does not even begin to convey my appreciation and respect for you in helping foster what was initially a very broad interest into this final product. It is because of you that I will be forever proud of this work and grateful that fate smiled upon me so as to have you as my graduate advisor. All graduate students should be so fortunate.

My Thesis Committee Members, Dr. Pat Franks of San José State University and Dr. Susie Aber of Emporia State University. Both of you have been wonderful sources of inspiration, support, wisdom, and advice. Immeasurably affable and knowledgeable, your doors have always been open, advice always spot-on, and professional and personal demeanors never once made me feel like I was intruding on your time. As with Debbie, all graduate students should come across and utilize those of your quality when performing graduate and professional research.

Rebecca Hamilton of the State Library of Louisiana, Jennifer Walker and Sharman Smith of the Mississippi Library Commission, and Peggy Price, Teresa Welsh, and Shugana Williams of the University of Southern Mississippi. You all promptly provided 
much valuable data and personal insight about this catastrophe as it related to Louisiana and Mississippi libraries to which I would not have otherwise had access.

The four Gulf Coast library professionals who participated in the survey in Chapter 5. All participants graciously provided valuable insight into their personal experiences and respective institutions' disaster planning effectiveness in light of this catastrophe.

Alena Filip of the Office of Graduate Studies \& Research at San José State University. Your prompt and informative responses to numerous inquiries made the IRB approval and thesis submittal process a smooth one.

Carrie Medders, Marilyn Radisch, and Michael Dunefsky from the CMS Project Office at San José State University. You all graciously allowed me to attain my MLIS degree while working at a full-time position at the CMS Project Office. I will be forever grateful for this generosity. Next to the definition of "higher education professionals" in the dictionary your pictures should be present.

Librarians Heather K. Moberly of Oklahoma State University, Stillwater, Oklahoma; Elaine Stefanko of the Osterhout Free Library, Wilkes-Barre, Pennsylvania; and Karen Tate Pettinger of the Portneuf District Library, Chubbuck, Idaho. You all have always been adamant in fostering in me the desire to pursue librarianship as a career. Your support for me in this regard has always been happily unwavering and positive.

My cats Mimi, Fifi, Baby, and CeCe. Their ever faithful presence lying at my side while I typed for hours at the computer was most appreciated. Providing needed 
affection when at the crossroads of numerous mental blocks have allowed this process to be that much more enjoyable.

My family and friends, living and deceased, who have been witness to much professional career soul-searching on my part over the years and provided more inspiration to me than you will ever know. You have all been so very supportive in all I have ever done and undertaken. Whenever I have expressed enthusiasm, doubts, frustration, or anything else related to the attainment of this degree, you were there, even if most of you thought "GIS" was some kind of new hybrid vehicle or weather satellite.

Finally, my wife, Connie. You have been my rock of stability and support over the years, especially during the past few while I was attaining my MLIS degree. Your feedback, suggestions, motivation, patience, honest critique, selflessness, and assuming of most dinner duties during this time have helped to make this thesis what it is now. You make life worth living and are the wellspring for my life's happiness. Love is not a big enough word for how I feel for you. 


\section{TABLE OF CONTENTS}

Page

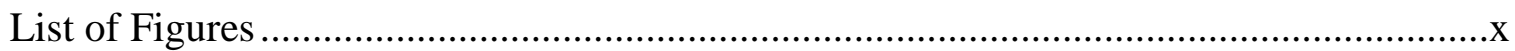

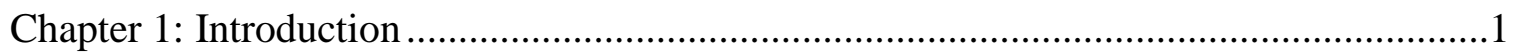

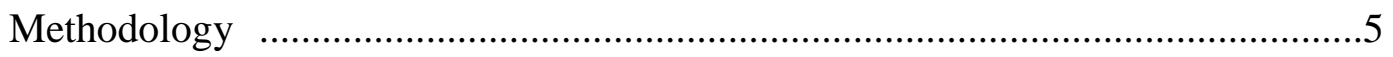

Chapter 2: Preparation and Warning before Hurricane Katrina ....................................10

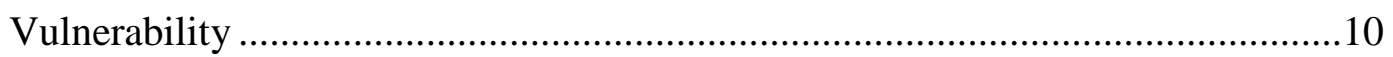

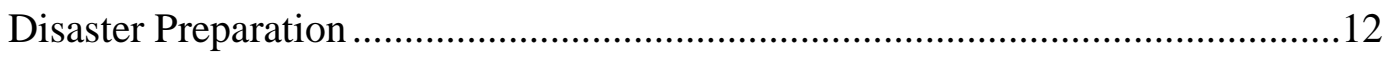

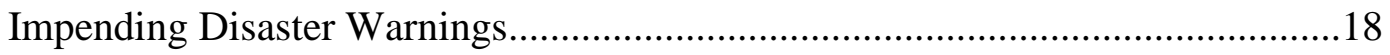

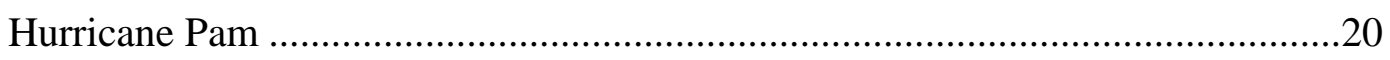

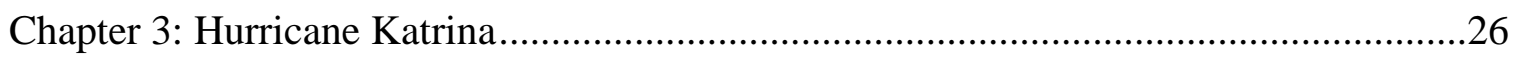

Hurricane Katrina Formation .....................................................................2 26

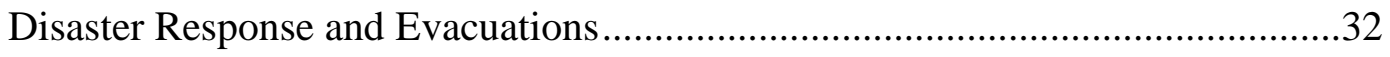

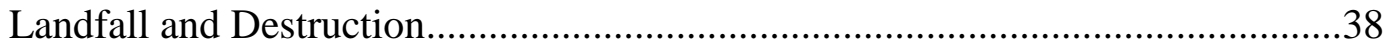

Chapter 4: Hurricane Katrina and Gulf Coast Libraries ..............................................43

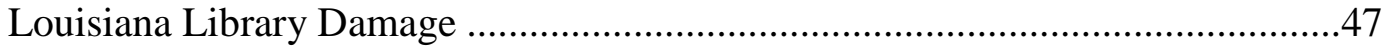

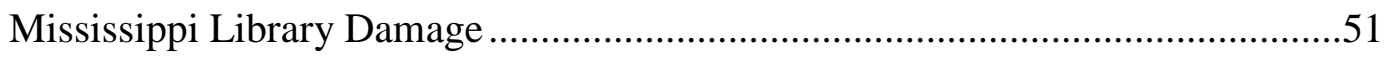

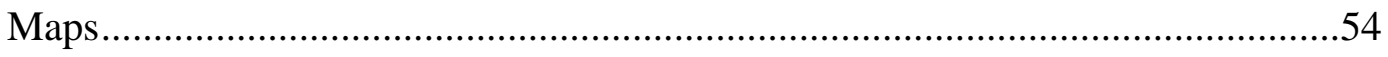

Chapter 5: Gulf Coast Libraries Case Studies ...........................................................61

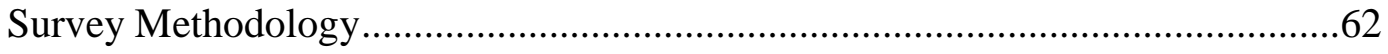




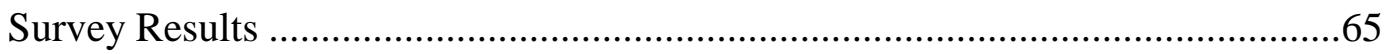

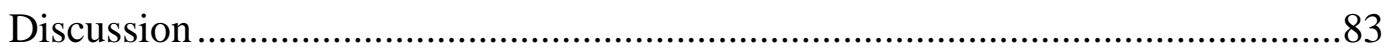

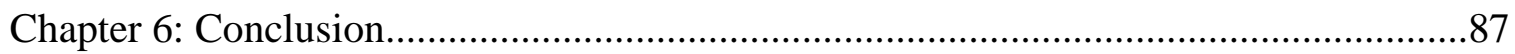

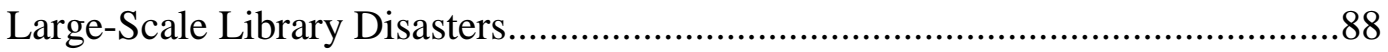

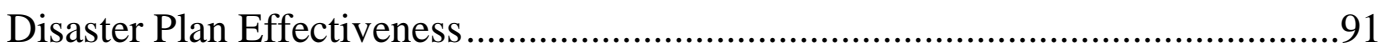

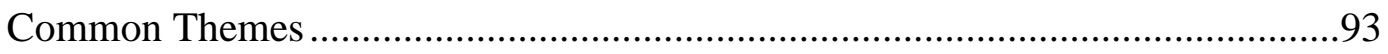

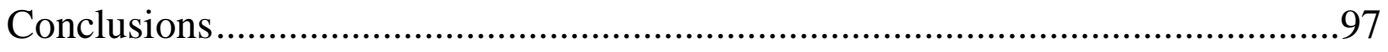

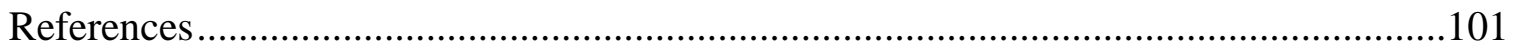

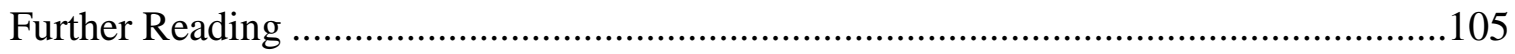

Appendix A: Survey Form Sent to Select Gulf Coast Librarians .....................................108

Appendix B: Louisiana Libraries Base Data (excluding New Orleans) ...........................109

Appendix C: New Orleans, Louisiana Libraries Base Data ..............................................111

Appendix D: Mississippi Libraries Base Data................................................................112 


\section{List of Figures}

Figure 1. Cross-section of New Orleans showing ground elevations

Figure 2. Hurricane Katrina track and intensity

Figure 3. NOAA-18 (Polar Orbiter) satellite image of Hurricane Katrina near peak intensity, August 28, 2005

Figure 4. Hurricane Katrina trajectory and wind speed (in knots), Monday, August 29, 2005

Figure 5. Location and severity of damaged southeastern Louisiana libraries (excluding New Orleans)

Figure 6. Location and severity of damaged New Orleans libraries .58

Figure 7. Location and severity of damaged Mississippi libraries 


\section{Chapter 1: Introduction}

"Disasters become disasters only when natural forces meet human ones." Dr. Matthew Mulcahy, Professor of History, Loyola University

On the morning of Monday, August 29, 2005, Hurricane Katrina made initial landfall in the Gulf Region near Buras, Louisiana, and later near the Louisiana and Mississippi border at Bay St. Louis, Mississippi. Packing sustained winds of $125 \mathrm{mph}(201 \mathrm{~km} / \mathrm{h})$, hurricane-force winds extended at least 75 miles $(121 \mathrm{~km})$ outward from the center of the storm. Because of its enormous size, the hurricane produced an astonishing Category 5strength 20 to 30 -foot (6- to 9-m) storm surge over a region that is at or below sea level in many places. Needless to say, Katrina's damage was incredible. Almost at once, the hurricane became infamous for its enormous size, intensity, and, most of all, the devastation it wrought.

In addition to Katrina's unprecedented magnitude, local, state, and federal authorities' inefficient preparation for the storm and lack of adequate response to its aftermath created one of the worst and most expensive natural disasters in the history of the United States. The federal government's inaction before and during this event is particularly appalling given that the Federal Emergency Management Agency (FEMA) had issued a report in early 2001 that ranked a catastrophic hurricane hitting New Orleans as one of the three most likely catastrophes to strike the country in addition to a terrorist attack in New York City and a devastating San Francisco earthquake. In spite of this

\footnotetext{
${ }^{1}$ Bergman, 2008, p. 936.
} 
acknowledged vulnerability, improperly maintained and inadequate levees in New Orleans, gradual destruction of wetlands in southeastern Louisiana, lack of a usable disaster plan, and miscommunication among local, state, and federal government officials before and following the hurricane all contributed to the severity of the disaster Katrina became. Compounding these problems was an overall increase in population along the Gulf Coast.

The cost of Hurricane Katrina was staggering in terms of human lives and property. People and landscapes in the Gulf Coast region are still recovering from it today. Over 1,800 people were killed as a result of the storm, with the overwhelming majority of the casualties occurring in Louisiana and Mississippi. Upwards of one million people were ultimately displaced from Louisiana alone. The estimated cost of the damage caused by Hurricane Katrina is over $\$ 80$ billion, by far the costliest natural disaster to occur in the United States.

The storm's impact on the region's libraries is equally appalling. According to the State Library of Louisiana's website, 42 library public buildings were completely destroyed or damaged as a result of the hurricane and the storm surge that followed (State Library of Louisiana, http://www.state.lib.la.us/, 2009). ${ }^{2}$ The Orleans Parish Library had 8 of 13 branches destroyed. Five of the 12 branches of the New Orleans Public Library system received extensive damage. In addition, three libraries in Plaquemines Parish had water up to their roofs; two St. Bernard Parish library facilities were completely submerged; and four of the 15 Jefferson Parish libraries were completely destroyed.

\footnotetext{
${ }^{2}$ This data is no longer available on the State Library of Louisiana website.
} 
Libraries and library collections in Mississippi experienced similar destruction. Many libraries along Mississippi’s Gulf Coast, especially those south of Interstate 10, were either severely damaged or completely destroyed.

This thesis will study Hurricane Katrina's impact on the Gulf Coast library community in two regions: the New Orleans, Louisiana, metropolitan area and the southern Mississippi area near the Gulf Coast. The time period for the research takes place primarily from when the storm made landfall in late August 2005 up to a year after the storm, though some of the disaster's effects, such as population displacement and economic recovery, continued past this period.

This topic is a significant one due to the lack of an in-depth historical treatment of what Gulf Coast libraries endured during and after the Hurricane Katrina disaster. Tales of how affected libraries weathered the storm, what damage they received, and how they came back from destruction (in many cases "better than ever") in a post-Katrina Gulf Coast world were prevalent in library trade journals immediately following the destruction. However, a history of their experiences has not been published as of this writing. Aggregating these individual library experiences and combining them in a discussion on disaster preparedness in an historical context seemed to be the logical next step. As a result, this work will be a useful addition to library and information science literature. This research is a stepping-off point for more historical analyses aimed at the examination of other libraries throughout the region, country, and world that are vulnerable to disaster, both natural and man-made. 
Therefore, it is the aim of this thesis to provide researchers with a focused history of how libraries endured one of the worst calamities to ever strike the United States. Research questions include:

- What pre-existing factors contributed to the level of destruction to New Orleans metropolitan and southern Mississippi libraries?

- What types of damage did libraries sustain and why?

- Because of their vulnerability to natural disasters (specifically hurricanes), what disaster plans were in place at select Gulf Coast libraries at the time of Hurricane Katrina's landfall?

- What remediation has taken place at select Gulf Coast libraries since Hurricane Katrina?

- What lessons have Gulf Coast libraries learned as a result of this ordeal?

Currently, the writings that exist about Hurricane Katrina and its impact upon Gulf Coast libraries are largely localized narratives by library professionals from the regional library community relating their experiences of coping and recovery during and after the event. More often than not, these are articles authored by a member or members of a particular library's staff or regional library association that use vivid descriptions of how much damage particular libraries sustained and what the resultant effects were, which ranged from suffering of some damage, but later reopening to being completely destroyed. Further, national library associations, such as the American Library Association (ALA) and Special Libraries Association (SLA), were instrumental in 
posting library status reports and disaster relief information on their respective websites. Finally, articles and books in both print and electronic format by historians, scientists, geographers, and climatologists, while not writing specifically on the theme of Hurricane Katrina and its effects on Gulf Coast libraries, provide valuable insight into the disaster and its far-reaching effects.

\section{Methodology}

The methodology for the compilation of this thesis included obtaining data from preexisting sources in print and electronic formats, contacting library professionals for library damage figures, collecting and processing the raw data provided by the aforementioned librarians to create maps via geographic information systems (GIS) software, and surveying selected Gulf Coast library professionals about their library's experience during the disaster.

Because several years had elapsed between Hurricane Katrina and the commencement of the research for this thesis, many information sources were available. The sources for the information used came from journal articles, books, documentaries, and websites. These sources primarily covered the topic of the effects of Hurricane Katrina on the Gulf Coast community as told from the perspectives of historians, scientists, filmmakers, and librarians. Other topics covered were how the region's library community was impacted by the disaster, disaster response, Gulf Coast vulnerability and disaster risk, and stories of international library disasters throughout history. In addition, much valuable insight, library damage data, and recovery information were gathered by 
personal email correspondence with Gulf Coast library professionals and library association representatives.

The creation of the maps was done for two reasons: to act as a visual aid so the researcher could see the extent of library damage and to archive GIS and historic data as it concerns libraries and Hurricane Katrina. The raw library data used for the maps were obtained through email correspondence with representatives of several library organizations, primarily the Mississippi Library Commission and the State Library of Louisiana. Once collected the data was input into an Excel spreadsheet to show, among other attributes, library locations in latitude/longitude coordinates and the degree of damage sustained during and after the hurricane. After this spreadsheet of Mississippi and Louisiana library locations and damage degree information was created, the next step was to locate and download the additional spatial data (such as county boundaries and storm surge flood extent) from a variety of resources such as the Mississippi Automated Resource Information System (MARIS), Atlas: The Louisiana Statewide GIS, and the Federal Emergency Management Agency (FEMA). Once the spreadsheet was completed, the data was uploaded into the GIS software to create a total of four maps. One map shows the trajectory of Hurricane Katrina on the day of landfall, August 29, 2005. The three other maps show the locations and degrees of damage suffered to libraries in southeastern Louisiana, New Orleans, and southern Mississippi. These three maps also show the extent of flooding in these regions caused by the hurricane's storm surge. 
In addition to background research and the creation of maps, the researcher surveyed several Gulf Coast library professionals to gain personal insight into the impact of the disaster on local libraries. After the survey was approved by the San José State University Human Subjects-Institutional Review Board, it was sent via email to these professionals whose facilities were damaged in some way by the storm. The librarians were selected for several reasons. The author sought to obtain a representative sample of institutions of academic, public, and governmental depository/archival libraries that were affected by Hurricane Katrina. Also, the library professionals representing each selected institution had various degrees of visibility in the professional library and information science literature either as authors of particular pieces or as interview subjects after the disaster. Finally, these subjects were selected due to their professional and personal experiences with their respective institutions before, during, and after Hurricane Katrina.

This survey was designed to obtain information from the respondents about both the damage from Hurricane Katrina to their respective institutions and their library's disaster preparedness at the time of the storm. It was comprised of eight questions that asked the subjects for their perspectives on disaster-related areas such as damage sustained at their institutions as a result of Hurricane Katrina, where most of the damage occurred, and how costly the damage was. Further, these professionals were asked to provide details about their library's disaster mediation measures that were in place at the time of Hurricane Katrina's arrival. Their perspectives regarding how well these measures mitigated damage to the libraries' staff, collections, and physical structures were obtained, as well as their thoughts on how the disaster influenced the library afterwards. 
This thesis is divided into six chapters. Chapter 1, the introduction, outlines the purpose and need for the history of Gulf Coast libraries during Hurricane Katrina, as well as its subsequent place within the realm of library disaster preparedness literature. Chapter 2 outlines the vulnerability of the Gulf Coast locations that were affected by Hurricane Katrina, as well as the preparation undertaken before landfall. Chapter 3 discusses the history of Hurricane Katrina and its impact upon the Gulf Coast, specifically to southeastern Louisiana and southern Mississippi. Chapter 4 focuses on how Hurricane Katrina impacted the Gulf Coast library community and the stories of what specific libraries endured. These narratives are augmented by several maps created from the raw data acquired from Gulf Coast library associations to provide visualization of the damage inflicted to academic, public, and government/archival libraries in southeastern Louisiana, New Orleans, and southern Mississippi. Chapter 5 reviews the results of a survey that was sent to four Gulf Coast library professionals. Each represented an academic, public, and governmental depository library facility that experienced varying degrees of damage from Hurricane Katrina. This chapter also details the damage to each library, whether there was a disaster plan in place at the time of the hurricane, how well the plan may have worked, and how the affected libraries responded to the crisis afterwards. The last chapter provides an evaluation of how well existing disaster plans mitigated the Hurricane Katrina crisis faced by the libraries from the survey. The chapter also looks at similar large-scale disasters at international libraries and the impact existing disaster plans had on protecting the collections. The chapter concludes with an analysis of the value of disaster plans during large-scale disasters such 
as Hurricane Katrina and what vulnerable libraries can do to help mitigate future damage from disasters. 


\section{Chapter 2: Preparation and Warning before Hurricane Katrina}

Hurricanes are nothing new to the United States and its coast-loving populations. Each summer on multiple occasions, one can tune into the evening news and expect to see hurricane coverage showing people preparing their homes against approaching wind and water, shopping madly at grocery stores (always seemingly outstripped of necessary items), and driving in the long lines of outgoing traffic. Hurricanes are so commonplace, in fact, that for years the Weather Channel has been regularly broadcasting from locations where hurricanes are battering the vulnerable coast. This was the case when Hurricane Katrina entered the Gulf of Mexico on Friday, August 26, 2005. While the entire region was threatened by the storm, perhaps no location was in more danger than the City of New Orleans.

\section{Vulnerability}

New Orleans was founded in 1718 by French-Canadian nobleman, Sieur de Bienville, as an ocean port at its present site on the Mississippi River because it was the only piece of high ground in the area. However, due to its location between Lake Pontchartrain and the Mississippi River, the area was still prone to flooding. Despite its "high ground" location New Orleans is primarily below sea level. In fact, historian Douglas Brinkley (2006) notes that "New Orleans had sunk to an average of six feet [2 $\mathrm{m}]$ below the waterline, and as much as eleven feet $[3 \mathrm{~m}]$ in some parts of the Ninth Ward and Lakeview" (p. 13). Director of Emergency Management for Jefferson Parish, Louisiana Walter Maestri describes metropolitan New Orleans as a bowl. "It looks like a 
gigantic soup bowl," Maestri explains. "We exist, on average, seven to ten feet below sea level" (NOVA, 2005). To make matters worse, New Orleans has no natural drainage and sits on a high water table. Finally, there is the issue with the soils upon which New Orleans is built. The city stands on sediment deposited by the Mississippi River, and these river-deposited sediments occupy a volume bloated by water content. According to regional geographer Richard Campanella (2008), "If the water drains away, organic matter disintegrates...allowing particles to become denser and more compact" (p. 326). The result is subsidence of the surrounding terrain. Dr. Ivor Van Heerden, deputy director of the Louisiana State University Hurricane Center in Baton Rouge, Louisiana, puts it in a similar way: "As those soils then become drained, the organic matter breaks down, just like compost, and so you lose bulk and the soils then shrink" (NOVA, 2005). When combined with levee building, soil subsidence has an even more pronounced effect. Campanella (2008) indicates that the levee construction and drainage-driven soil sinkage has "transformed New Orleans' topography from a slightly above-sea-level plain interspersed with higher ridges, to a series of bowls half above and half below sea level, surrounded by high brims" (p. 329). Thus, the immediate future did not bode well for New Orleans for several reasons, including being situated between the Mississippi River and Lake Pontchartrain, lying mostly below sea level, having no drainage, and being built upon compacting soil. 


\section{Disaster Preparation}

The Select Bipartisan Committee to Investigate the Preparation for and Response to Hurricane Katrina (2006) indicated that in early 2001, FEMA published a report that ranked the three most likely catastrophes to affect the United States. These were "a terrorist attack in New York City, a major earthquake in San Francisco, and a major hurricane hitting New Orleans" (p. 469). Residents of New Orleans, Louisiana, and the Mississippi Gulf Coast have long lived with this reality of their vulnerability from hurricanes. Both regions are at or below sea level and border on the Gulf of Mexico, long a breeding ground and highway for hurricanes. As noted above, New Orleans is particularly susceptible due to, among several reasons, its existence in a series of sub-sea level bowls and being bordered by the Mississippi River and delta complex to the south and Lake Pontchartrain to the north. New Orleans residents were all too aware of its precarious location and susceptibility to flooding, particularly in an event like a hurricane.

One of the ways that New Orleans combated its regular flooding was through a system of levees, built and maintained by the Army Corps of Engineers. Levees are flood-control measures. They consist of embankments made of dirt, some of which may be topped with concrete walls called "flood walls." In New Orleans, these levees range from a height of 13 to 18 feet ( 4 to $6 \mathrm{~m}$ ). The city's dependence upon them for protection against flooding from the Mississippi River and Lake Pontchartrain goes back to the

city's beginnings. Brinkley (2006) notes that Sieur de Bienville, the founder of New 
Orleans, experienced first-hand how easily flooded his new town would be and "immediately started work on the city's first levees, earthen berms that would protect the land from floodwater" (p. 6). Little did de Bienville know how intertwined his city and its flood protection measures would become many years later.

Averaging almost 60 inches $(152 \mathrm{~cm})$ of rain annually, the land on which New Orleans is built is actually sediment deposited by the Mississippi River. As historian Ari Kelman (2007) explains, "The highest ground is found along the river frontage... [Then] the land slopes down—roughly fifteen feet over a distance of about one and a half miles" gradually toward the back of the city "where much of the ground is below sea level" (pp. 696-697). As years passed and New Orleans grew, so did the system of levees needed to protect its expansion. Areas that were previously swamp or marshland were reclaimed and assimilated into the city as it grew. The levee system expanded accordingly.

Over time, the United States Army Corps of Engineers (USACE) was to become responsible for the oversight of this system of levees. Once the levees were built by the USACE, they were then turned over to several organizations called "sponsors." Once a sponsor accepts a levee (called a "project") from the USACE, it is the sponsor's responsibility to operate and maintain it. After the sponsor's acceptance, the USACE may no longer allocate federal funds toward improvements, though this does not pertain to repair after a flood. After initially sponsoring most of the levees around New Orleans, the Louisiana Department of Transportation and Development then turned over control of individual levees to local sponsors. The responsibility for different parts of the Lake 
Pontchartrain and vicinity for example, was given to several different sponsors. In this case, the sponsors were four levee districts (East Jefferson, Orleans, Lake Borgne, and Pontchartrain). The levee districts often worked to maintain the levees on an individual basis and not as a team. This multitude of heterogeneous sponsors eventually resulted in operation and maintenance attention given only to their respective portions of the levee, often with different materials being used between wall and levee systems at transition points. At these transition sections of the levees where different organizations met, levee breaches often occurred even before Hurricane Katrina. Further complicating the efficiency of such a needed protection was the existence of separate water and sewer districts that maintained different pumping stations. Thus, a lack of coordination and cooperation among these sponsors only contributed to the decay of the levee system's integrity.

The levee area to be maintained is immense. Brinkley (2006) states that "the New Orleans District of the Corps administered 30,000 square miles [78,000 sq. km], all of Southern Louisiana, the most complex section of the United States in terms of water control and...the busiest, measured by shipping traffic" (p. 8). Focusing on the immediate New Orleans area, Campanella (2008) points out the Orleans Parish Levee Board "maintained...twenty-eight miles [45 km] of levees and floodwalls and seventythree floodgates along the Mississippi River, plus another 101 miles [163 km] of levees and 107 floodgates along Lake Pontchartrain and the navigation and outfall canals" (p. 207). Figure 1 shows a map that is a cross-section of New Orleans as it lies between the 
Mississippi River and Lake Pontchartrain, protected from flooding by both floodwalls and levees.

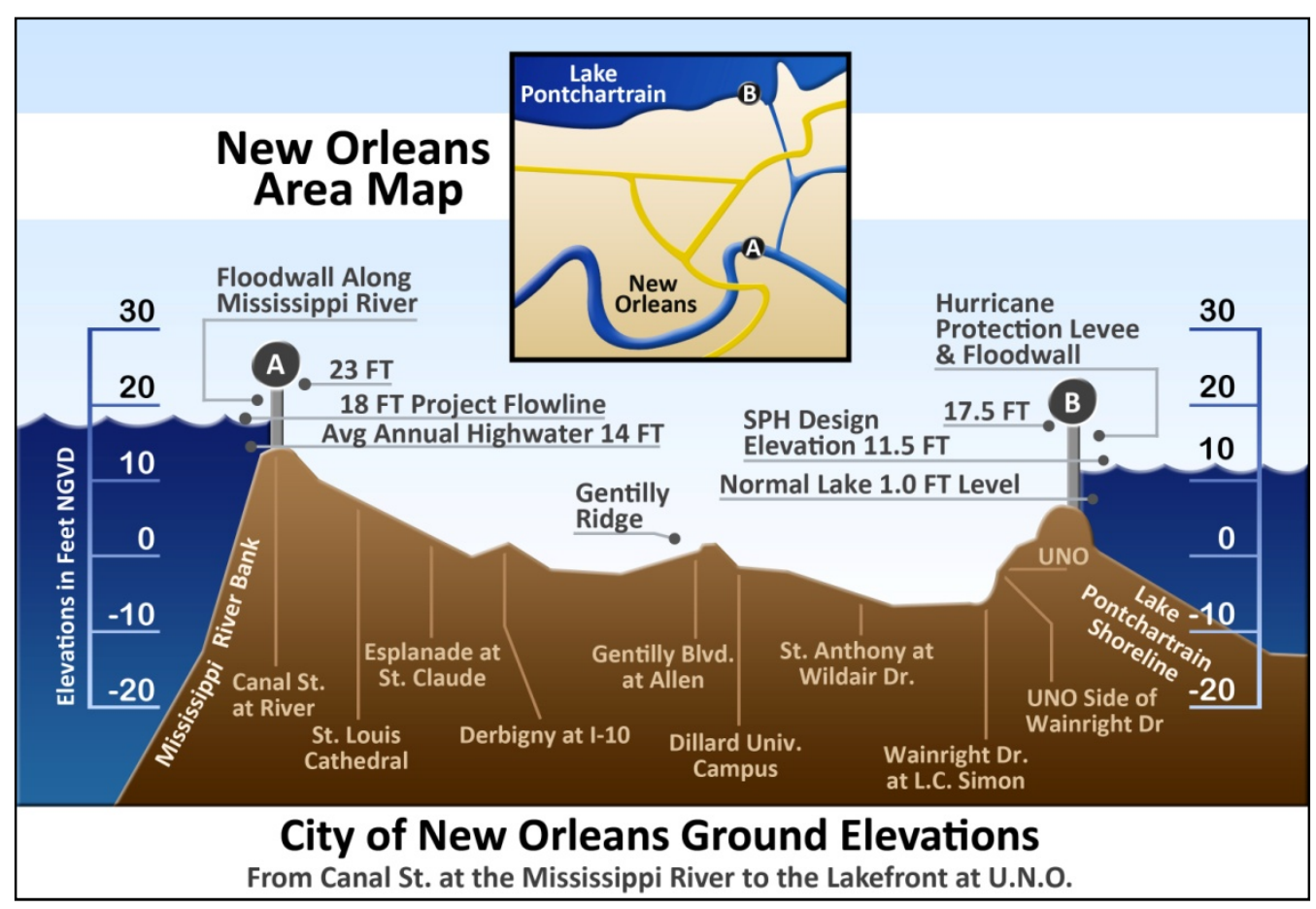

Figure 1. Cross-section of New Orleans showing ground elevations. Adapted from "City of New Orleans Ground Elevations: From Canal St. at the Mississippi River to the Lakefront at U.N.O.," by Alexdi, 2009. Retrieved from http://en.wikipedia.org/wiki/File:New_Orleans_Elevations.jpg. Copyright 2009 by Alexdi. Reprinted with permission.

Even with this protection built by the USACE and managed by local levee districts, these levees were not designed to withstand the most severe hurricanes and, indeed, would likely fail to protect the metropolitan area where they were positioned. This was admitted by Col. Richard Wagenaar, a member of the USACE, who said in regard to the quality of the levees at the time of Hurricane Katrina, "A lot of the construction or current-day construction was in the sixties. The floodwalls were all finished early-1990s. 
The system we were working on was a system to withstand a fast-moving Category 3" (NOVA, 2005). According to the Southern Regional Climate Center (2011), the hurricane category scale is from one at the lowest, termed a tropical depression, to five at the highest, a hurricane with winds over $155 \mathrm{mph}(249 \mathrm{~km} / \mathrm{h})$. Hurricane Katrina, while a Category 3 hurricane at the time of landfall, brought along with it an immense Category 5 storm surge. In addition, because the USACE had different local sponsors overseeing the maintenance of the levees in their sections, there were potential weaknesses in the levees at transition sections. As the Select Bipartisan Committee (2006) explained after the disaster, "Different organizations were responsible for different pieces and, thus, two different levee or wall systems [were] joined together" (pp. 91-92). While Hurricane Katrina would expose the weaknesses of the levees and floodwalls for the world to see, they essentially failed as a result of a lack of proper levee maintenance, little to no coordination among levee district sponsors, and an outdated protection system.

Further, while the levee system has a number of benefits, such as providing bountiful croplands and making vulnerable areas like New Orleans habitable, levees can also sow the seeds of destruction. Problems with levees include soil subsidence and coastal erosion acceleration. Levees also encouraged land development that lured homeowners into hazardous flood plains (Campanella, 2008). Another problem with the levee system is that they starve the wetlands of the Mississippi River Delta of silt and this sediment was not replenished. As a result wetlands have been disappearing at a rate of 20 sq. meters a year (NOVA, 2005). This is a serious issue, considering the protection wetlands provide the Louisiana coast from the devastating effects of storms and floods. In regard 
to hurricane storm surge protection, Van Heerden (2006) describes wetlands, along with barrier islands, as "the best, most natural, least expensive buffer available" (p. 169). The extent of wetland deterioration over the years has accelerated to the point that their ability to protect the Louisiana coast has greatly diminished.

Farther east along the populous Mississippi Gulf Coast, levees did not play as significant a role in protection as they did in New Orleans, though both regions are equally at the mercy of water during a hurricane. At the time of Hurricane Katrina, no levees, sea walls, or similar man-made structures protected the low-lying communities of the three coastal counties of Mississippi from the ravages of the storm surge. This is all the more striking especially when considering how population had increased along the Gulf Coast in recent decades.

The Mississippi Gulf Coast, while not at risk from the kind of flooding New Orleans faces, is vulnerable to hurricanes, particularly from the accompanying storm surge. Storm surge is the heart of a hurricane's destructive power and causes the most catastrophic damage. Simply put, the storm surge is an enormous mound of water that is generated by the high winds of a hurricane and pushed across the open ocean. A particularly strong hurricane can generate a storm surge in excess of 20 feet $(6 \mathrm{~m})$ or more. Along the 100-mile (160-km) stretch of the Mississippi Gulf Coast lie cities and towns that are situated directly on the coast itself. Communities such as Waveland, Gulfport, Biloxi, and Pascagoula are more or less completely exposed to the fury of a Category 3 or stronger hurricane. Also, most of these coastal communities do not have 
natural or man-made protection to absorb or deflect the storm surge. Here, a hurricane need only arrive and the storm surge will do the rest.

\section{Impending Disaster Warnings}

While other areas of the Gulf Coast are also at risk, its unique predicament and extreme susceptibility to flooding made New Orleans especially stand out during and after the crisis. The Select Bipartisan Committee (2006) noted that during the aftermath of Hurricane Katrina, then-President Bush publicly stated on September 2, four days after the storm made landfall, "I don't think anybody anticipated the breach of the levees" (p. 464). To suggest that New Orleans, its history so intertwined with levee protection, was indeed ignorant of the threat of levee failure before Hurricane Katrina does a grave disservice to the efforts of those who did their best to make people in the New Orleans metropolitan area as aware as possible of the problem.

Since the 1980s, scientists and government officials regularly attempted to send warnings of impending flooding doom that the Crescent City and surrounding region faced. In 1989, John McPhee's The Control of Nature painted a grim picture of how the levees built by the Army Corps of Engineers would eventually succumb to natural processes (as cited in Brinkley, 2006). In 1998, then-National Hurricane Center Director Jerry Jarrell publicly conveyed a recurring nightmare in which a powerful Category 4 or 5 hurricane ravaged the Caribbean, cut northwest through the Miami metropolitan area, entered the Gulf of Mexico, and eventually slammed into New Orleans (Select Bipartisan Committee, 2006). It should be noted that most of his premonition came true for the Gulf 
Coast with Hurricane Katrina. In June of 1999, Frank Hijuelos, the then-New Orleans Office of Emergency Preparedness Director, publicly recommended that city residents (if able) try to evacuate the city upon the first official evacuation requests in light of computer modeling results by Louisiana State University (LSU) and federal agencies that showed a slow-moving Category 3 hurricane overtopping the levees (Select Bipartisan Committee, 2006). In a 2001 Scientific American article "Drowning New Orleans," Mark Fischetti had similarly dire predictions:

New Orleans is a disaster waiting to happen. The city lies below sea level, in a bowl bordered by levees that fend off Lake Pontchartrain to the north and the Mississippi River to the south and west. And because of a damning confluence of factors, the city is sinking further, putting it at increasing flood risk after even minor storms. (As cited in Brinkley, 2006, p.14)

Over the next few years, warnings continued to appear in governmental reports and the popular media. For example, from June 23-27, 2002, the Times-Picayune (the major New Orleans newspaper) ran a five-part series that illustrated the dangers that New Orleans faced. In July of 2004, the warning coordination meteorologist for the National Weather Service's Southern Region, Walt Zileski, similarly worried about the city's safety from flooding as a result of a hurricane based upon studies of its vulnerability.

An October, 2004 National Geographic story, “Gone with the Water," provided what would become a prophetic glimpse into a New Orleans battered by a Category 3 or higher hurricane. The article describes the scenario of a severe hurricane that causes a 
major evacuation of over a million people, though hundreds of thousands (mostly poor and aged) remain. Floodwaters, augmented by the hurricane, pour into New Orleans as they top levees. This deluge, 25 feet $(\sim 8 \mathrm{~m})$ deep in some places, forces those riding out the storm to escape to their homes' roofs. Thousands die as a result and many more thousands are made homeless (Bourne, 2004). The similarities between how this fictional hurricane and Hurricane Katrina played out are eerie to say the least.

\section{Hurricane Pam}

Perhaps the most significant opportunity to prepare for impending hurricane disaster came in 2004, as a result of a FEMA-funded week-long disaster preparedness exercise held at the Louisiana State Emergency Operations Center in Baton Rouge. Attended by federal, state, and local officials, the exercise was designed to develop a joint disasterresponse plan in anticipation of the catastrophic hurricane that would inevitably strike the New Orleans area. According to Dr. Walter Maestri, Director of Jefferson Parish's Emergency Management, this exercise was done, "so the locals knew what their responsibilities were, the State knew what their responsibilities were, and the Federal Government knew what its responsibilities were" (National Geographic, 2005).

The most significant product of this disaster preparedness exercise was the "Hurricane Pam" simulation, in which a strong Category 3 hurricane strikes New Orleans. The track of the "hurricane" was developed by the National Weather Service and based on the path of Hurricane Georges from 1998, which turned only hours before it would have made landfall near New Orleans and likely would have overtopped the 17- 
foot $(5 \mathrm{~m})$ levees in the city. This computer-generated storm "had sustained winds of 120 $\mathrm{mph}(193 \mathrm{~km} / \mathrm{h})$ and up to 20 inches [51 cm] of rain fell in parts of Southeast Louisiana. In addition, storm surges overflowed the levees and flooded New Orleans" (Select Bipartisan Committee, 2006, p. 81). As a result of the levee failures, Greater New Orleans was inundated with ten feet ( $3 \mathrm{~m}$ ) of water. As the simulated Hurricane Pam progressed, New Orleans residents were forced to evacuate. If they refused to do so, up to 500,000 would be left stranded in not only floodwaters, but what Brinkley (2006) would later call a "HAZMAT 'gumbo"” (p. 18).

The science behind the computer modeling was sound and the potential impact of Hurricane Pam was revealed in terrifying detail:

1. 300,000 would not evacuate in advance.

2. 500,000 to 600,000 buildings would be destroyed.

3. Phone and sewer services would be knocked out and chemical plants would be flooded.

4. $97 \%$ of all communications would be down.

5. About 175,000 people would be injured, 200,000 would become sick, and more than 60,000 would be killed.

6. About 1,000 shelters would be needed for evacuees.

7. Boats and helicopters would be needed for thousands of rescues because many residents would be stranded by floodwaters. 
8. A catastrophic flood would leave swaths of southeast Louisiana uninhabitable for more than a year. (Select Bipartisan Committee, 2006, p. 81)

In predicting such grave losses and catastrophic failures, the Hurricane Pam simulation forced local, state, and federal emergency management agency representatives participating in the exercise to acknowledge and address the situation. According to Ron Castleman, FEMA Regional Director, "We made great progress this week in our preparedness efforts. Disaster response teams developed action plans in critical areas such as search and rescue, medical care, sheltering, temporary housing, school restoration and debris management" (FEMA, 2004, para. 3). The Hurricane Pam exercise also forced state health officials to better prepare for special needs people and hospital patients, as well as made clear what FEMA was supposed to do during a disaster to the region. Another result of one of the exercise's workshops was the creation of the Southeast Louisiana Catastrophic Hurricane Plan, which provided general guidance for local emergency management planners. This plan was in effect for the 2005 hurricane season (Select Bipartisan Committee, 2006).

Unfortunately, some issues were left unclear or were not addressed during the Hurricane Pam exercise. Though some management agencies, such as Louisiana Wildlife and Fisheries and the Coast Guard, developed disaster response plans and procedures, much of what happened after Hurricane Katrina showed that many problems had not been addressed despite the Pam exercise. For example, it was not until Katrina 
struck that it was discovered that an estimated 127,000 residents did not have cars for evacuation. Van Heerden and Bryan have also pointed out that there was a large number of homeless and disabled living in the city who also were unable to evacuate (as cited in Lee, 2006). Interestingly, while planners of the Hurricane Pam exercise had discussed organizing a second program to address the needs of low-mobility residents, it never materialized (Van Heerden \& Bryan, 2006).

There was also an apparent misunderstanding among the participants about the roles and responsibilities of particular entities. This was particularly true in the case of FEMA. After the exercise, some state officials interpreted some of the emergency management responsibilities discussed as being carried out by the federal government, but in the days after Hurricane Katrina it was obvious that they did not carry out those duties to which they had committed to doing. One of the exercise's more notable participants Dr. Walter Maestri, the Director of Emergency Management for Jefferson Parish, complained that FEMA in particular failed to meet its responsibilities during Katrina. According to Maestri, while FEMA may not have been able to provide assistance for up to 48-72 hours later, after that FEMA should have supplied affected areas with food, water, and ice. However, substantial relief from FEMA did not arrive in Jefferson Parish until 11 days after landfall (Select Bipartisan Committee, 2006).

On the other hand, the designer of the simulation, Baton Rouge-based Innovative Emergency Management, Inc. (IEM) and FEMA tell a different story. A representative from IEM claims that the plan derived from the exercise was intended as a guide to be 
further developed by the state and local governments. A FEMA representative similarly complained that state and local governments did not complete certain "to do" items (Select Bipartisan Committee, 2006). It was the view of one FEMA official that in all the areas where the state was supposed to develop more detailed planning (including rapid assessment teams and search and rescue), only one area (medical evacuation) saw progress (Select Bipartisan Committee, 2006). Though the Hurricane Pam exercise brought about positive results, clearly there was substantial miscommunication on what roles federal, state, and local entities were responsible for during a similar crisis.

The Hurricane Pam exercise was certainly worthy of being conducted, but final results were flawed. For all the preparation put into the simulation, it could not predict all of the disaster-related complications that Hurricane Katrina exposed the following year. The exercise was also criticized for the emphasis it seemingly placed on managing the catastrophe's aftermath rather than on designing preventative measures (Select Bipartisan Committee, 2006). Also, some of the concepts and plans that were designed were never implemented or not fully implemented. The previously mentioned second Pam exercise that would have focused on how to deal with the high numbers of immobile New Orleans residents had it ever materialized is an example of just this kind of shortcoming. Finally, there was the issue of the participants not taking the exercise seriously (Van Heerden \& Bryan, 2006). Indeed, according to Brinkley (2006), "to most Louisiana officials, discussing Pam was akin to reading A Thousand and One Nights; it was make-believe" (p. 19). Brinkley's (2006) accusation was corroborated by Clancy Dubos, publisher of the local weekly Gambit "Before Katrina," Dubos complained, 
“people looked at Pam exercises like kids do fire drills in school. They just weren't going to take it seriously until it happened" (as quoted in Brinkley, p. 19).

In summary, much has been written on the vulnerability of the Gulf Coast. It is one of the most (if not the most) vulnerable locations for hurricanes to strike in the United States. In southeastern Louisiana and southern Mississippi, substantial populations located along the coast live in low-lying areas prone to flooding. These areas, particularly in southeastern Louisiana and New Orleans, are also faced with compacting soils and decreasing numbers of barrier islands that serve as natural protection from the effects of storm surges. With New Orleans' existence in constant danger of flooding due to its precarious location between the Mississippi River and Lake Pontchartrain, the city is protected by an intricate system of levees and floodwalls. However, responsibility and communication issues over the years among levee districts contributed substantially to their deterioration prior to Hurricane Katrina. Also, the presence of these levees stymie the natural process of silt deposition as a result of periodic flooding by the Mississippi River, which starve the region of much needed natural material to build up the terrain. Similarly, the Mississippi Gulf Coast is particularly vulnerable to storm surges primarily due to being at sea level with little protection. The Hurricane Pam exercise of 2004 did result in more awareness of this vulnerability, but left questions regarding responsibility not clarified. The following year would see the occurrence of a truly devastating hurricane that would test the region's disaster response and mitigation capabilities. 


\section{Chapter 3: Hurricane Katrina}

The storm system that brought such devastation and misery to the Gulf Coast region had humble beginnings in the tropical regions of the Atlantic Ocean (see Figure 2). All tropical storms and hurricanes begin as a thunderstorm or group of thunderstorms in the tropical latitudes. The National Hurricane Center (2006) details that what would eventually become Hurricane Katrina had complex roots involving "the interaction of a tropical wave, the middle tropospheric remnants of Tropical Depression Ten, and an upper tropospheric trough" (p. 1). Still 175 miles $(282 \mathrm{~km})$ southeast of Nassau in the Bahamas on Tuesday, August 23, 2005, the National Hurricane Center upgraded the storm to a tropical depression, making it the twelfth tropical depression of the 2005 hurricane season. The following morning, this tropical depression was upgraded to Tropical Storm Katrina. It was now centered approximately 65 miles $(105 \mathrm{~km})$ eastsoutheast of Nassau.

\section{Hurricane Katrina Formation}

Moving toward Florida, Tropical Storm Katrina was upgraded again on Thursday to a Category 1 hurricane, with sustained winds of 74-95 mph (119-153 km/h) (NOAA, 2010). Almost as soon as Tropical Storm Katrina became Hurricane Katrina, it made its first United States landfall in southern Florida. This occurred at 6:30 p.m. between Hallandale Beach and Aventura, Florida. The hurricane quickly travelled over the relatively narrow strip of land that is southern Florida and commenced reorganization in the eastern Gulf of Mexico. On Friday morning, August 26, Hurricane Katrina, now in 
the warmer waters of the gulf, became a Category 2 hurricane with sustained winds between 96-110 mph (154-177 km/h) (NOAA, 2010).

Once Katrina had been upgraded to a Category 2 hurricane, both Louisiana and Mississippi declared a state of emergency, which, among other powers, allowed the governors of the affected states to deploy National Guard troops and suspend civil liberties if necessary. By 11:00 p.m., Friday night, the National Hurricane Center predicted that Hurricane Katrina "would make landfall near Buras in southeastern Louisiana," which is 60 miles [97 km] southeast of New Orleans (National Geographic, 2005). In regard to New Orleans, a city most vulnerable to tropical storms, weather forecasters had already begun to look toward the Crescent City as being a potential target by the soon-to-be monstrous Katrina. By the time the National Weather Service issued an updated weather advisory at 5 a.m. on Saturday, August 27, forecasters were predicting the storm to move toward the city (Brinkley, 2006). 


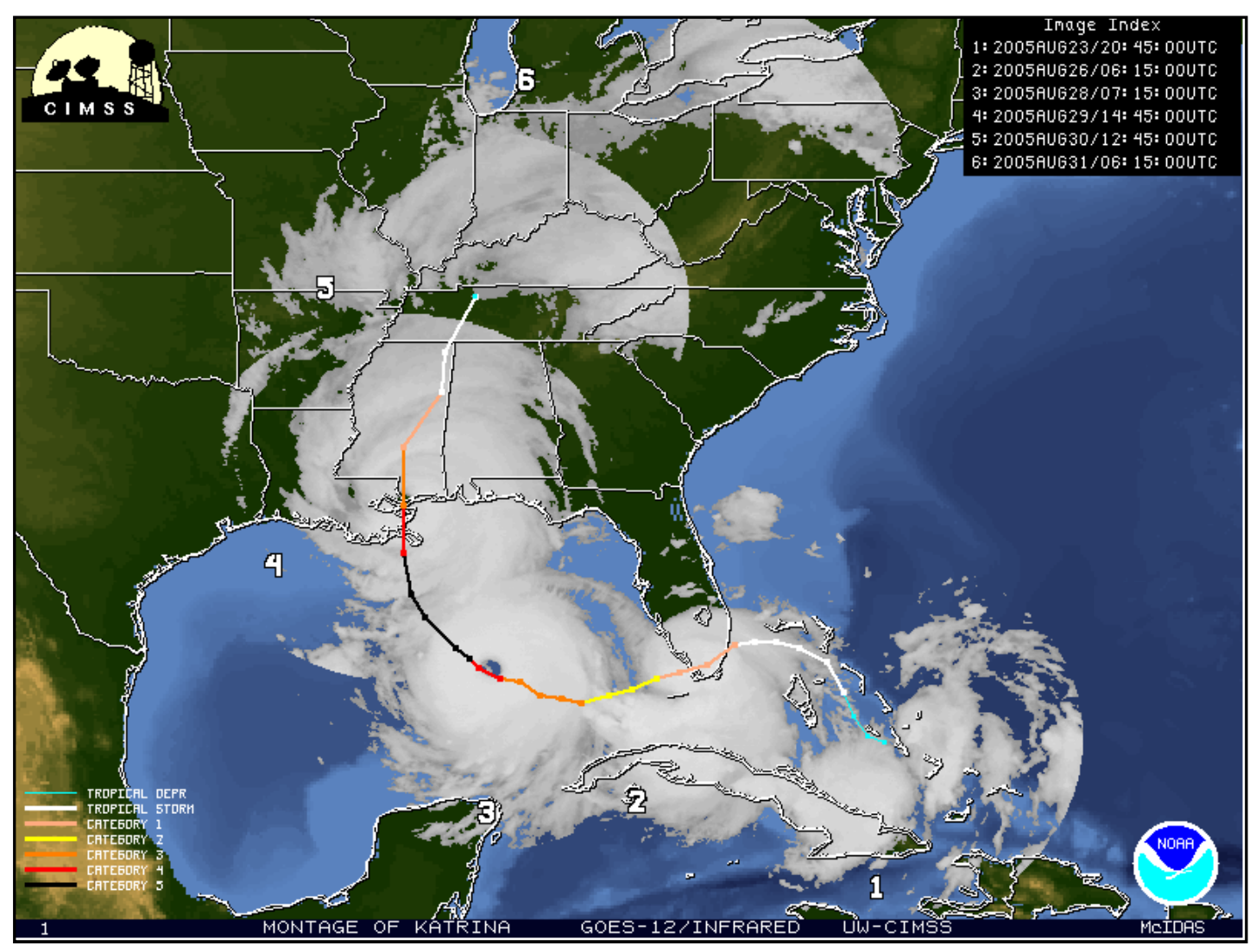

Figure 2. Hurricane Katrina track and intensity. Source: NOAA's National Climatic Data Center, 2005 http://www.ncdc.noaa.gov/oa/reports/tech-report-200501z.pdf

Reorganized after passing over southern Florida and now in the Gulf of Mexico, the storm took advantage of the warm surface water of what is known as the Loop Current. "The Loop", as it is known, is an extension of the Gulf Stream ocean current and can be powerful enough to prevent cooler water from rising to the surface. When this happened in August 2005, the warm waters nourished Katrina as the hurricane progressed toward the Louisiana coast (Van Heerden \& Bryan, 2006). Because hurricanes gain energy the longer they travel over warm water, Hurricane Katrina became increasingly potent. As 
Van Heerden and Bryan (2006) explain, as deep warm waters benefit hurricane growth, "it is not at all coincidental that hurricanes often strengthen over the Western Caribbean, where the warmest layer of water can be over three hundred feet deep [91 m]" (p. 29).

Certain meteorological conditions, then, conspired to set in motion Hurricane Katrina's infamous trajectory as it moved west into the Gulf of Mexico. As a result, the storm continued to grow in size and strength in the warm waters of the Gulf of Mexico, as it moved westward on Saturday, August 27, then along a northwesterly track on Sunday, August 28, and finally north on Monday, August 29. The atmospheric and seasurface conditions were conducive to optimal hurricane building, and the storm rapidly intensified during this time. There couldn't have been better conditions for growing the perfect hurricane. 


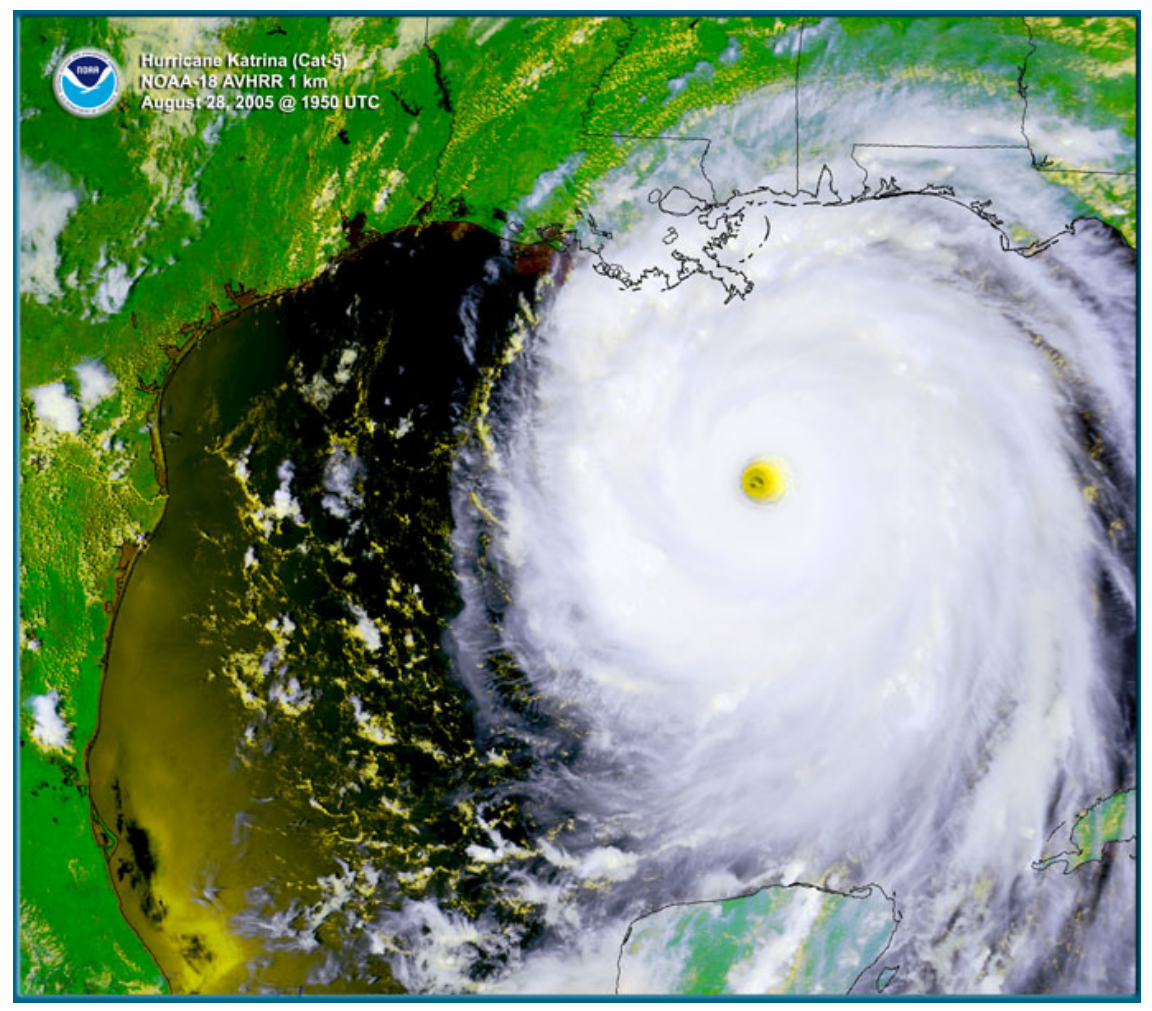

Figure 3. NOAA-18 (Polar Orbiter) satellite image of Hurricane Katrina near peak intensity, August 28, 2005. Source: NOAA's National Climatic Data Center, 2005 http://www.ncdc.noaa.gov/oa/reports/techreport-200501z.pdf

By Saturday, August 27, Hurricane Katrina’s winds passed $115 \mathrm{mph}(185 \mathrm{~km} / \mathrm{h})$, making it a powerful Category 3 storm. On this same day there was significant expansion of the storm's wind field, which nearly doubled in size (see Figure 3), with tropical storm-force winds extending to approximately 140 miles $(225 \mathrm{~km})$ from the center. According to Graumann et al. (2006), by late Sunday morning, Hurricane Katrina's “maximum sustained wind speeds peaked near $175 \mathrm{mph}[282 \mathrm{~km} / \mathrm{h}]$ and remained at that speed until the afternoon." They also note that hurricane force winds were "extending outward up to 105 miles [169 km] from the center and tropical storm force winds extending outward up to 230 miles [370 km]." At the same time, Katrina's 
"minimum central pressure dropped to $902 \mathrm{mb}$ [millibars] — the fourth lowest on record at that time for an Atlantic hurricane" (p. 2). Put simply, this means that the lower a hurricane's central pressure, the higher the winds will be, the larger the storm surge will be, and, thus, the stronger the hurricane is. Now a Category 5 hurricane, Hurricane Katrina set its sights on the Gulf Coast.

Because of their low elevations, all locations along the Gulf Coast were vulnerable to the hurricane's storm surge, which is the mound of water created when the hurricane's winds, blowing at high speed, push across the open sea. Storm surges are so deadly, in fact, that even with the high winds associated with a hurricane, $90 \%$ of all hurricane deaths occur from drowning (NOVA, 2005). The gravity of the potential consequence of a large storm surge was evident in the National Hurricane Center's initial hurricane watch and warning, issued 41 and 32 hours, respectively, prior to Katrina's landfall. The Category 5 storm's size, low central pressure, and high wind speed all contributed to the creation of an enormous storm surge. As a result, the purpose of these warnings for the communities located around the Gulf of Mexico was to prepare the population for truly incredible destruction and to quickly evacuate if necessary.

Despite the National Hurricane Center's early and accurate landfall prediction, there wasn't enough time to evacuate such a heavily populated region. According to Jefferson Parish's Director of Emergency Management, Dr. Walter Maestri, "It takes between 60 and 72 hours to evacuate," twice the amount of time available (NOVA, 2005). Moreover, 
no locality along the Gulf Coast had adequately prepared for a storm of this magnitude. This was "the big one" regional emergency planners and weather forecasters had feared.

\section{Disaster Response and Evacuations}

The Gulf Coast community lives with the threat of hurricanes, and it is a fact of life for those who live there. So, it is not surprising that prior to Hurricane Katrina's landfall, disaster responses and evacuations overall went relatively smoothly in southeastern Louisiana and southern Mississippi. However, disaster preparation efforts and evacuations in New Orleans were hampered by the unnecessarily delayed evacuation order that came less than 24 hours prior to landfall. Also, city officials' lack of familiarity with its disaster plan contributed to not fully preparing the city as it ought.

Among the first to recognize the imminent danger were Louisiana State University professors Dr. Ivor Van Heerden and Dr. Hassan Mashriqui who input the available data being gathered about Hurricane Katrina into the previous year's Hurricane Pam computer model. Their calculations clearly showed that the storm was indeed going to flood New Orleans. Van Heerden sent out email after email to communicate his concern to city officials. Van Heerden recalled 'We knew on Saturday night that this was 'the big one', that it was going to sink New Orleans. So we tried to get the word out as much as possible" (NOVA, 2005).

Despite dire warnings from both the National Hurricane Center and Van Heerden, government officials were not conveying the urgency to the populace. In fact, at 5 p.m. on Saturday evening Governor Kathleen Blanco, who had traveled to New Orleans for a 
press conference, issued a joint statement with New Orleans Mayor Ray Nagin that a "voluntary evacuation order had been issued for the city in anticipation of Katrina" (Brinkley, 2006, p. 55). Though the incoming meteorological data by this time was indicating the increased likelihood of a direct hit to New Orleans, a mandatory evacuation was still not issued at this time. Suggesting a rationale for why the evacuation order was “voluntary", Brinkley (2006) explains, "The year before, [Hurricane] Ivan had been on a similar path, heading straight for New Orleans, but it swerved eastward at the last minute. ... So, the illogic went, Katrina would probably do the same thing" (p. 55).

By Saturday night, Max Mayfield, Director of the National Hurricane Center in Miami, in Florida, was in constant communication with government officials at all levels, much of it directly by phone, to warn of Katrina's impending danger to New Orleans. The normally calm Mayfield expressed great concern to the officials, as well as to Governor Blanco, and eventually Mayor Nagin (Mayfield had a difficult time reaching him). He emphasized that while the storm at this point could technically still go anywhere in the gulf, his data models were showing both a direct hit on New Orleans and that the storm was not done strengthening (Brinkley, 2006). According to Director of Emergency Management for Jefferson Parish, Louisiana, Dr. Walter Maestri, Mayfield was not one to take these matters lightly and if he actually contacted you personally by phone, then that meant he was gravely concerned. "When he calls you like that," Maestri stated, "He's telling you you need to be ready, be prepared" (as quoted in Brinkley, 2006, p. 58). 
On the morning of Sunday, August 28, with Hurricane Katrina now having Category 5 hurricane status, it was poised to do incredible damage to the Gulf Coast, particularly in southeastern Louisiana. The situation was now dire enough for the Office of the National Weather Service, located in Slidell, Louisiana, to issue one of the most strongly-worded, vivid warnings in its history. Issued at 10 a.m. in a desperate attempt to warn as many people as possible, it read, in part:

Devastating damage expected....Hurricane Katrina....a most powerful hurricane with unprecedented strength....rivaling the intensity of Hurricane Camille of 1969....Most of the area will be uninhabitable for weeks...perhaps longer. At least half of well constructed homes will have roof and wall failure. All gabled roofs will fail....leaving those homes severely damaged or destroyed....Water shortages will make human suffering incredible by modern standards. (Select Bipartisan Committee, 2006, p. 108)

It was at this point that Governor Blanco and Mayor Nagin finally ordered a mandatory evacuation of the citizens of New Orleans, 56 hours after the first warnings had been conveyed to them. As mentioned earlier, one of the rationales behind their slow response was their experience with Hurricane Ivan the previous year. Both hurricanes followed a similar path to New Orleans, but Ivan missed the city altogether at the last minute (Brinkley, 2006). Because the evacuation for Hurricane Ivan turned out to be a false alarm, it can be inferred that officials wanted to avoid the hassle and embarrassment of a repeat empty exercise. 
However, once the evacuation of New Orleans began, the disaster planning proved effective. Using what is called a "contra-flow" traffic system, cars streamed out of the city. This process was conducted until 6 p.m. on Sunday and worked efficiently with the neighboring states of Texas and Mississippi since the affected Louisiana interstates crossed state boundaries. As Brinkley (2006) describes it:

At 4 p.m. on Saturday, the Louisiana State Police turned over all lanes to outward traffic on four New Orleans interstate highways. The metro area's two toll roads, the Crescent City Connection and the Lake Pontchartrain Causeway, were now free. Called "contra-flow", the redirected traffic represented the one plan that the state had worked out in enough detail to operate effectively in the face of Katrina. Governor Blanco oversaw the creation of the surprisingly complex contra-flow plan after the bottleneck traffic debacle caused by the approach of Hurricane Ivan in September 2004. (p. 54)

Final disaster preparations and evacuations throughout southeastern Louisiana and southern Mississippi gained steam as Hurricane Katrina approached the Gulf Coast. Evacuations in southeast Louisiana had begun as early as 9:00 a.m. on Saturday morning. That region already had an evacuation plan in place, which included activating National Guard troops and coordinating plans among all parishes to follow (Select Bipartisan Committee, 2006). Other southeastern Louisiana parishes were beginning to issue mandatory evacuations. St. Bernard Parish, for example, ordered one on Saturday, not waiting until New Orleans had issued theirs. Since evacuations in southern parishes had 
begun almost 24 hours prior to New Orleans's evacuation order, evacuees did not experience traffic bottlenecks as they traveled through urbanized areas like New Orleans and Baton Rouge to places of refuge. To assist residents without vehicles to evacuate, there were nongovernmental programs to help. One such program is the "Brother's Keeper" program in New Orleans and Jefferson Parish that helps residents without vehicle access to evacuate, with the latter parish also utilizing a volunteer-run phone bank that matched up riders with drivers once the evacuation was announced. Evacuation shelters were set up along the evacuation routes. Several parishes established "shelters of last resort" for those residents who either could not evacuate or had delayed leaving past the point when it was possible. The most infamous of these shelters was the Superdome in New Orleans. In anticipation of such an event, the Superdome had been stocked with “9,792 meals, ready to eat (MREs) and 13,440 liters of water." However, these provisions as well as sanitation facilities were inadequate for the number of people who ultimately sought shelter there and for the length of time it was occupied after the storm. Local transit service brought stranded New Orleans residents to the Superdome as well as to shelters in Baton Rouge.

Outside of Louisiana, evacuations proceeded smoothly. Five Mississippi counties (Hancock, Jackson, Harrison, Stone, and Pearl River) issued mandatory evacuations on or before the hurricane struck on August 29. While Mississippi does not have a city with the metropolitan population akin to New Orleans along its coast, there are a number of coastal cities and towns such as Gulfport, Biloxi, and Pascagoula that required coordinated efforts to effectively evacuate them. Mississippi Governor Haley Barbour 
had the authority to order mandatory evacuations if local officials did not, but he did not order one because he felt that since county officials were much closer to the action they would know if and when a mandatory evacuation was to be issued. For example, Hancock County, one of Mississippi's three coastal counties, issued mandatory evacuations for zones A \& B (Gulf front and other low-lying areas) at 10 a.m. on Sunday; in those areas designated as zone $\mathrm{C}$ (highest elevations of the county) evacuations were strongly advised but not mandated. Like New Orleans, Mississippi counties used the contra-flow traffic flow evacuation, and the system worked effectively. Additionally, the Mississippi Emergency Management Agency (MEMA) determined that coastal counties would not open local shelters so as to encourage people to evacuate north. Since these coastal county shelters were located at or just above sea level and, thus much more exposed than farther inland, they were only to be opened as a last resort.

For all those who chose to evacuate, there was a substantial number of people who didn't. Those who stayed had a variety of reasons, including wanting to ride the storm out, not wanting to go through the motions of evacuating for another Hurricane Ivan, not wanting to leave their pets behind, not being able to evacuate the area due to no money, transportation, or place to go, or being just traffic-phobic (Brinkley, 2006). These motives, along with the failure of government officials to issue an earlier mandatory evacuation, resulted in more than 70,000 people remaining in New Orleans to face the storm (Select Bipartisan Committee, 2006). 


\section{Landfall and Destruction}

By Monday, August 29, Hurricane Katrina had finally reached the end of its journey over the Gulf of Mexico and began a siege of widespread destruction and misery along the Gulf Coast, primarily in Louisiana and Mississippi. What would follow would be one of the worst natural and human disasters in the history of the United States. In addition to its substantial wind speed, the storm also brought an enormous storm surge that simply overwhelmed the region and man-made protections, including levees and floodwalls. When the storm had finally departed, the human and financial toll was almost beyond comprehension.

Hurricane Katrina made initial landfall in southeastern Louisiana near Buras in Plaquemines Parish at approximately 6:10 a.m. and a second landfall at around 10:00 a.m. near the Louisiana-Mississippi border. During its movement northward through the gulf over the previous 18 hours, the storm experienced substantial weakening from its earlier Category 5 status due to a number of factors, including lower water temperatures. However, the storm was still a considerable Category 3 hurricane with sustained wind speeds of $127 \mathrm{mph}(204 \mathrm{~km} / \mathrm{h})$ at landfall. Upon landfall, the storm also brought 8 to 10 inches (20 to $25 \mathrm{~cm}$ ) of rainfall to southeast Louisiana and southern Mississippi. Along the Mississippi coast, the storm also brought a 20-foot (6-m) storm surge. In some places the water rose even higher. While the storm surge remained highest on the east Mississippi-side of the eye of the hurricane, the area on the west Louisiana-side also received a significant storm surge via Lake Pontchartrain. 
Without a doubt, the strong winds played a substantial role in the damage to manmade structures. Among the most significant damage was done to the roof of the Superdome - now serving as an evacuation shelter-which included two 6-foot (2-m) holes being ripped open above the field. However, it was the storm surge that far and away did the most damage. Most of Katrina's destruction in New Orleans was caused by the widespread flooding when the floodwalls and levees failed. Because of the Category 5 storm surge and the lack of storm surge buffers in the form of wetlands, the water was free to impose its will on the coast. Early on the morning of Monday, August 29, a 14- to 17-foot (4- to 5-m) surge of water shot up into what is known as "the Funnel," the place where the Mississippi River-Gulf Outlet (MR-GO) and the Intracoastal Waterway merge in the Industrial Canal. This confluence of water punched a 400-yard (366-m) hole in the canal's flood wall, allowing water to inundate the eastern section of the city. As Van Heerden (2006) explains:

To the south this water poured into the communities that were already taking on water through the MR-GO breaches, now including the Lower Ninth Ward. To the north it poured into the neighborhoods in the adjacent bowl in Orleans Parish, between the Intracoastal Canal and Lake Pontchartrain. (p. 83)

At the same time, Lake Pontchartrain's water level rise due to the influx of hurricane storm surge was putting strain on the city's other canal floodwalls, most notably the $17^{\text {th }}$ Street Canal (northwest of downtown) and the London Avenue Canal (north of downtown). Both canals inevitably experienced pressure bursts where the floodwalls 
were pushed out and away from the canal due to the peaty soil. In all, 53 levees were breached, and a staggering $80 \%$ of the greater New Orleans area was flooded (National Geographic, 2005).

In Mississippi, coastal devastation was near total. The winds had blown at a steady $125 \mathrm{mph}(201 \mathrm{~km} / \mathrm{h})$ with gusts to over $160 \mathrm{mph}(257 \mathrm{~km} / \mathrm{h})$, turning everything not tied down into an airborne weapon. Brinkley (2006) notes that, "From garbage-can lids to Ford 150 truck doors to Maytag refrigerators to 120 -foot [36.5-m] yachts, Katrina made shrapnel of everything" (p. 159). And, as in Louisiana, there was the storm surge to consider, which, according to the Hancock Emergency Operations Center reached as high as 27 feet $(8 \mathrm{~m})$ and traveled inland from 6 to 12 miles ( 9 to $19 \mathrm{~km})$. In the Gulfport and Biloxi areas, storm surges surpassed those of Hurricane Camille by anywhere from 5 to 10 feet $(8$ to $16 \mathrm{~km})$. The damage caused by the water was enormous. In fact, in Waveland, Mississippi $80 \%$ of its dwellings were rendered uninhabitable. Two of the region's main bridges, the Bay St. Louis Bridge and the Biloxi Ocean Springs Bridge, were similarly destroyed. Many of the Mississippi coast casinos floating on barges were damaged or destroyed as well. Brinkley (2006) describes the scene in which one-third of [Jackson] county residents lost their homes. In Pascagoula, from the beach to the railroad track, everything had been submerged under twenty feet [6 m] of water" (p. 177). All along the Mississippi coast, the storm surge erased all manners of man-made structures, telephone poles, and even many old-growth oaks from the landscape. 
Hurricane Katrina's winds and floods caused widespread damage and precipitated human and economic costs rarely seen in the modern-day United States. Brinkley (2006) soberly points out, "Katrina has impacted 90,000 square miles [234,000 $\left.\mathrm{km}^{2}\right]$ —an area equivalent to the size of Great Britain" (p. 637). It caused $\$ 81$ billion dollars worth of property damage and took 1,833 lives. Of these deaths, 1,577 occurred in Louisiana and 238 in Mississippi. The Gulf Coast region from Louisiana to Alabama was declared a federal disaster area, with an estimated 284,000 homes destroyed. In New Orleans alone, approximately 60,000 houses were eventually declared damaged beyond repair (NOVA, 2005). The Mississippi coast was also a disaster area. Stripped of greenery and homes, the Mississippi coast, as Brinkley describes it, "looked like a product of the scorchedearth policy initiated by William Tecumseh Sherman during the Civil War" (p. 173). And neighboring states were affected as well, with over one million residents evacuating from southeastern Louisiana and Mississippi to other regions, including other parts of Louisiana, Alabama, even as far away as Chicago, Illinois. Texas alone absorbed 220,000 refugees.

In summary, Hurricane Katrina was particularly costly, due to the region's general lack of preparedness, the inadequacy of the levees, and communication breakdowns during and after the disaster. As Theodore Steinberg states, "Disasters are 'unnatural' events with individuals and governments complicit in the production of links in the disaster chain" (as quoted in Bergman, 2008, p. 936). In the case of Hurricane Katrina, the preparation and response became the benchmark for how not to prepare for an impending crisis, one for which the region had long since been made aware. A lack of 
viable and practiced disaster plans was most notable in New Orleans. Further, mandatory evacuations in some cities, counties, and parishes were not enforced early enough.

Disaster response was, on the whole, painfully slow, inadequate, and ill-communicated, all contributing to create a disaster of inconceivable proportions.

With so many individuals and institutions affected by Hurricane Katrina, libraries did not escape the disaster. The next chapter will take a more focused look at how libraries in southeastern Louisiana and southern Mississippi fared during the crisis. 


\section{Chapter 4: Hurricane Katrina and Gulf Coast Libraries}

The previous chapter showed the extent of the destruction wrought by Hurricane Katrina to the Gulf Coast in general. The storm caused many billions of dollars in damage to the region's infrastructure and economy, yet its people suffered the most. Thousands lost their lives, while many more were rendered homeless and forced to live in other parts of the country for an indeterminate amount of time. As incredible as it was, the scope of the damage in the Gulf Coast region was neither unexpected nor unforeseen. The region's proximity to the Gulf of Mexico and its vulnerability to the hurricanes spawned there have long been a concern to emergency management officials.

Yet, as hindsight has shown, there were ways officials might have been better prepared for the disaster and could have taken action to mitigate some of the hurricane's impact. Better communication and quicker action among local, state, and particularly federal officials would have likely resulted in more efficient disaster relief after the storm had passed. Given the region's elevation at near sea level—or, as in the case of the New Orleans metropolitan area, below sea level—-the most obvious precaution would have been to improve the structural integrity of the levees and floodwalls in southeastern Louisiana. Another issue affecting the quality of levee protection of New Orleans and southeastern Louisiana was the presence of shipping channels that, by a combination of erosion and allowing saltwater from the Gulf of Mexico to infiltrate the freshwater marshes, destroyed many of the wetlands. The most notorious of these channels is the Mississippi River-Gulf Outlet (MR-GO). Had this channel not been built, there would 
have been more protective wetland area to absorb Katrina's storm surge. Along the equally vulnerable Mississippi Gulf Coast, where damage was most severe primarily due to the enormous storm surge, protections like barrier island restoration, seawalls, levees, floodgates, and beach replenishment would have likely played some role in reducing the level of damage.

Not to be spared, the libraries of the Gulf Coast also suffered enormously from Katrina, particularly those in southern Mississippi and southeastern Louisiana because of their close proximity to where the storm made landfall. While the storm was amply anticipated so that library staffs swiftly prepared for and responded to the natural disaster, many libraries and collections nonetheless suffered due to the high winds and water.

Libraries in both southeastern Louisiana and southern Mississippi were in the crosshairs of Hurricane Katrina when the storm came ashore. Because of their vulnerable location, there was no denying one simple fact: libraries were going to sustain damage. It was just a matter of how much. Ultimately, it was their respective locations that determined the extent of damage each library would sustain. Figure 4 shows the storm's trajectory and wind speed on Monday, August 29, 2005, the day of the storm's landfall. It is worth noting that New Orleans was positioned directly in the center of the hurricane's path. In Mississippi, the enormous storm surge to the east of this path was indiscriminate as it devastated cities and towns along the coastline of the state's three coastal counties, Hancock, Harrison, and Jackson. 
Hurricane Katrina's damage to libraries in southeastern Louisiana and along the Mississippi coast was staggering. While some damage stemmed from the storm's wind, most of libraries' damage occurred as a result of flooding caused by the storm surge. In New Orleans, libraries' water damage was primarily caused by storm surge-induced flooding brought about by canals' breaching and overtopping numerous levees and floodwalls, as well as from flooding from Lake Pontchartrain. This spelled disaster for the libraries in a city that was built within a series of bowls at or below sea level. In other areas of southeastern Louisiana, flooding was caused by the storm's 8 to 10 inches (20 to $25 \mathrm{~cm}$ ) of rain.

As in Louisiana, Mississippi libraries sustained some wind damage, particularly farther north after the storm made landfall. However, it was the water damage from the storm surge that caused the lion's share of library damage to facilities located along the Mississippi coast. Here the surge extended anywhere from 6 to 12 miles $(\sim 9-19 \mathrm{~km})$ inland (mainly along bays and inlets) and at heights approaching 30 feet $(9 \mathrm{~m})$ in some areas. In the end, the damage to these libraries' collections and physical structures depended primarily upon their location and, to a degree, how prepared each library was in the face of the impending hurricane. The level of damage libraries sustained varied by location as well. Damage ranged from minor leaks as a result of broken windows and mold outbreaks to significant flooding of buildings. For the purposes of this study, damage levels have been classified into categories of "minor", "moderate", "severe", and "none". The category of "none" was included to cover several libraries in Washington 
Parish, Louisiana, that were not immediately damaged by Hurricane Katrina but were closed afterwards due to financial problems related to the disaster.

Libraries were considered to have minor damage if they suffered several broken windows, minimal water damage (primarily due to leaking through windows and roofs), minor roof damage, and/or some mold growth post-Katrina. Libraries with this classification have already been repaired and have reopened. On the subsequent maps (Figs. 4-7), they are represented as green library icons.

Libraries were considered to have moderate damage if structural damage and mold was more extensive. This damage included multiple window breaks and/or hole(s) in the roof, caused by a combination of wind and/or flooding. Increased levels of mold growth post-Katrina were likely to be encountered in these structures. Furniture and computers were also destroyed if left unprotected. However, these libraries were still considered recoverable and have already been repaired and reopened. These libraries are represented on the maps by yellow library icons.

Libraries were considered to have sustained severe damage if they experienced total or near-total destruction. This kind of catastrophic damage would be the result of a combination of flooding and high winds. Rampant mold growth, substantial to total destruction of library collections, and significant damage to the physical structure of the library building itself would all fall under this category. Most of these libraries have been rebuilt either on the same site or at another location, though there are several that did not reopen. These libraries are represented on the maps by red library icons. 
It should be noted that complete, official data estimating total damage to the Gulf Coast library community does not exist. After contacting the American Library Association (ALA), it was learned that the organization did not collect this data. While there are existing pockets of data conveying the damage done to Gulf Coast libraries by Hurricane Katrina, this information focuses on specific types of libraries in an overviewtype of format. For example, the State Library of Louisiana and the Mississippi Library Commission have both provided valuable information on damage to public library branches, but not for academic or repository libraries. Some data was obtained through library publications or the parent institution, but it is by no means comprehensive.

\section{Louisiana Library Damage}

Many libraries in southeastern Louisiana experienced great devastation from Hurricane Katrina. As shown in Figure 4, the storm's path traversed over the southeast portion of the state. Thus, the heaviest damage occurred in Jefferson, Orleans, Plaquemines, St. Bernard, St. John the Baptist, St. Tammany, and Washington Parishes (see Figure 5). All across southeastern Louisiana, libraries had little choice but to brace themselves the best they could and begin implementing their respective disaster plans. This would have included the activation of measures intended to protect libraries' respective collections (either as securely as possible on-site or by removing them to safer/higher ground), securing the physical building, and, finally, removing library personnel from harm's way. Damage to libraries was primarily caused by high winds and severe flooding. The degree of damage ranged from minor to severe, with many 
libraries being declared total losses. In all, of the 188 public libraries in Louisiana, 23 were destroyed, 33 suffered severe damage, and 37 had moderate damage (Clareson \& Long, 2006, p. 38).

While at the last minute New Orleans was spared a direct hit by the storm when the hurricane shifted to the northeast, the city still suffered extensive damage, primarily as a result of the flooding caused by breached levee walls. The New Orleans Public Library (NOPL) system sustained damage estimated between \$26 to \$30 million dollars (Clareson \& Long, 2006). Additionally, it is estimated that a total of 320,000 items in the NOPL system's collections were lost (Huddleston, 2007). According to the State Library of Louisiana, 6 NOPL branches were declared destroyed: East New Orleans; Martin Luther King, Jr.; Nora Navra; Rosa Keller; Robert E. Smith; and Norman Mayer Gentilly. In these locations, libraries were swamped by up to 12 feet ( 4 m) of water. (State Library of Louisiana, http://www.state.lib.la.us/, 2009). ${ }^{3}$ Flooding was so severe at 5 other branches that equipment, materials, and sheetrock were sufficiently damaged by water and mold that they all had to be replaced (Oder \& Rogers, 2005, p. 18). In addition to the damage to buildings and collections, many New Orleans Public Library System's staff positions had to be cut as a consequence of the disaster. Indeed, the NOPL reduced its staff from 197 to 19 people. Other southeastern Louisiana parish libraries experienced great damage as well. Water almost reaching the roofs of the Port Sulphur and Buras Branches of the Plaquemines Parish Library System resulted in their being declared complete losses, while in the Jefferson Parish Library System 8 of its 15 branches

\footnotetext{
${ }^{3}$ This data is no longer available on the State Library of Louisiana website.
} 
suffered serious damage. Three of these branches were labeled as destroyed or unusable, another two suffered major damage, and two more experienced moderate damage (Oder \& Rogers, 2005, p. 19). Located north of New Orleans, the Washington Parish main library had a large pine tree crash into it which effectively destroyed the building. Elsewhere, the Lafourche Parish Library lost its roof; one library was destroyed and another severely damaged in St. Tammany Parish; and the main branch of the St. Bernard Public Library experienced severe flooding. The State Library of Louisiana notes that the Lakeshore Public Library in Jefferson Parish had a third of the roof destroyed, all books on bottom shelves were completely destroyed, and walls were ultimately removed due to extensive damage. Other data from the Louisiana State Library indicates that the Gretna Public Library in Jefferson Parish saw its new roof completely destroyed with most of its collections either damaged or destroyed (State Library of Louisiana, http://www.state.lib.la.us/, 2009). ${ }^{4}$

Louisiana public libraries were not the only institutions to see damage to their buildings and collections. Numerous academic libraries in the state, especially those in New Orleans, experienced various degrees of damage as well. Tulane University, Xavier University, Loyola University, University of New Orleans, Dillard University, and Southeastern Louisiana University were among the academic institutions hardest hit by the hurricane (see Figure 6). The actual cost of the damage is staggering. Xavier University sustained more than $\$ 47$ million in damages and Dillard University around \$500 million. Tulane University, doubling as a federal depository library, was the

\footnotetext{
${ }^{4}$ This data is no longer available on the State Library of Louisiana website.
} 
hardest hit in New Orleans, with eight feet $(\sim 3 \mathrm{~m})$ of water flooding the basement of its Howard-Tilton Memorial Library. Approximately 700,000 print volumes and recordings lay underwater for three weeks (Levack, 2008, p. 16).

Elsewhere, damage was not so extensive or immediate, but still considerable. At the University of New Orleans, for example, the library is located on high ground near the center of campus. However, a large hole in the roof that was punched in by the storm allowed much rain into the collection. Without power for air conditioning mold grew in the damp, humid environment (Jumonville, 2007). Xavier University flooded as a result of the collapse of the $17^{\text {th }}$ Street and London Avenue canals, which inundated the entire campus with 2 to 11 feet (1 to $3 \mathrm{~m}$ ) of water. Fortunately, Xavier's Library Resource Center experienced the least amount of flooding, with only the ground floors being affected (Skinner, 2006, p. 184).

The damage sustained by Louisiana libraries was caused by both wind and water, as well as subsequent mold outbreaks. However, the heaviest damage was the result of flooding, most notably in New Orleans. Many library branches were so heavily damaged so as to be declared total losses, collections of all forms were damaged or destroyed, and library staffs were greatly reduced in the wake of recovery from the disaster. However, not all libraries were so gravely affected, as most were repaired and permanently reopened either at the same or nearby location, with temporary service provided in the interim. 


\section{Mississippi Library Damage}

With little natural or man-made protection from the Gulf of Mexico, Mississippi libraries along the coast had to contend with an unimpeded Category 5 storm surge that extended inland a considerable distance. As a result, libraries in Mississippi's three coastal counties—Hancock, Harrison, and Jackson—-suffered extensive damage to both their buildings and collections. In addition to this coastal damage, library damage occurred significantly inland as well (see Figure 7).

Most of the severe damage to Mississippi libraries was caused by the enormous storm surge churned by Hurricane Katrina. Extending anywhere from 6 to 12 miles ( 9$19 \mathrm{~km}$ ) inland, all man-made structures were at its mercy. The hurricane's 34-foot (10-m) tidal surge destroyed four library buildings in Harrison County's library systemthe Biloxi Branch, the Gulfport Branch, the D'Iberville Branch, and the Division Street Study Center. Miraculously, although the D’ Iberville Branch building was ruined, its collection was spared (Clareson \& Long, 2006, p. 38). On the other hand, the Gulfport Branch building was beyond repair and many materials were destroyed; the collection loss amounted to approximately 75,000 items. At the Biloxi Branch, there was a toxic sludge present after the hurricane that prevented anyone without biohazard gear from entering the building. Standing in $4-5$ feet ( 1 to $2 \mathrm{~m})$ of water, the library lost most of its contents and was later condemned (Eberhart et al., 2005, p. 23).

Other Mississippi public libraries suffered considerable damage as well. In the Hancock County Library System, the Pearlington Branch in Bay St. Louis lost everything 
and the structure was completely gutted (Eberhart et al., 2005). The Bay St. Louis Public Library experienced considerable water and roof damage, and while the Waveland Library is still standing it too suffered significant structural damage and had to be gutted. In the Jackson-George Regional Library System, the Pascagoula Branch had taken on water, resulting in an extensive mold outbreak, costing up to 60,000 volumes. Elsewhere, the Long Beach Public Library was partially destroyed. Ultimately, the building was condemned, and the collection was listed as a total loss. The Shubuta Branch of the East Mississippi Regional Library, located well inland but directly in the path of the stillpotent hurricane, was rendered a total loss and the building was also condemned (Teresa Welsh, personal communication, August 10, 2010).

Damage to academic libraries in Mississippi was widespread, though not as severe as experienced in Louisiana. Most notably affected were the University of Southern Mississippi (USM) libraries at its three teaching sites: the Joseph Anderson Cook Library and William D. McCain Library and Archives in Hattiesburg; USM- Gulf Coast Library in Long Beach; and the Gunter Library on the campus of the Gulf Coast Research Laboratory in Ocean Springs. The Joseph Anderson Cook Library and the William D. McCain Library and Archives suffered minor damage. For example, the office of the Director for the School of Library and Information Science, located in the library, was destroyed as a result of the window blowing out, while other areas of the library had leaking windows. Also, there was water damage from a leaking second floor expansion joint. Elsewhere, water poured through openings caused by detached ceiling tiles. At the William D. McCain Library and Archives, there were only leaks around some of the 
windows on the third floor, wet carpeting which affected filing cabinets, and a damaged Halon fire suppression system (Wall, 2006, p. 192).

Damage, however, was more substantial at the USM library facilities in Long Beach and Ocean Springs. At the USM-Gulf Coast Library in Long Beach, the campus experienced a 20 -foot storm surge, extensively damaging many buildings on the campus. While the building experienced no structural damage, Mississippi Libraries (2005) reported:

The first floor received 12 to 18 [30 to $46 \mathrm{~cm}$ ] inches of water. There were some minor leaks around windows on the upper floors, and the carpet and upholstered furniture were soaked, and there was mud on the floor. Items on the bottom shelves received water damage. . . Mold/mildew grew rampantly due to lack of power and air conditioning. (p. 94)

At the Gunter Library at the Gulf Coast Research Laboratory in Ocean Springs, the building received about 18 inches $(46 \mathrm{~cm})$ of flood water and mud, ruining items on the bottom shelves (Wall, 2006). According to the Mississippi Libraries (2005) report, nearly 1300 items from the collection were damaged and would have to be replaced.

In terms of damage from Hurricane Katrina, the libraries in Mississippi fared as badly as, if not worse than, their counterparts in Louisiana. This is especially true for public libraries, where their proximity to the Gulf Coast without any real protection made them especially vulnerable to the Category 5 storm surge. Academic libraries, on the other hand, did not experience as much major damage primarily because the largest 
collections were located further inland such as in Hattiesburg. However, the academic libraries located closer to the coast in Long Beach and Ocean Springs did endure some damage because of their proximity to the storm surge.

\section{Maps}

An appreciation for the magnitude of the impact of the storm can best be illustrated through the use of maps. For Figures 5-7, it is important to note that the data regarding library damage is based on information provided by the Louisiana and Mississippi State Libraries, much of which is no longer available electronically (see Appendixes B, C, and D for base data). Figure 4 shows the path the storm took over the northern portion of the Gulf of Mexico and as it made landfall on Monday, August 29, 2005. Figure 5 shows the degree of damage suffered by libraries in southeastern Louisiana (with the exception of those in Orleans Parish) from Hurricane Katrina and the resultant flooding. As detailed in the previous chapter, the flooding in Southeast Louisiana occurred as a result of the storm surge pushing up the Mississippi River, shipping channels, and into Lake Pontchartrain. Eventually, the enormous burden of water traveled up these channels and into the lake, flooding New Orleans via overtopped and failed floodwalls and levees. Most Louisiana libraries that were affected by Katrina were located in low-lying areas near water sources, such as shipping canals and Lake Pontchartrain. Of particular note are the four libraries in Washington Parish that have a damage classification of none. In the case of these libraries, they received only minimal damage, but were later closed due to financial difficulties incurred during the recovery period. Figure 6 shows the degree of 
damage suffered by libraries in Orleans Parish (primarily New Orleans) and the flood extent as of Wednesday, August 31, 2005. It should be pointed out that the libraries that sustained major damage in New Orleans were primarily located in the flooded zones, which is represented by the sky-blue shaded area. Those libraries represented as receiving minor or moderate damage are either at the edge of the flooded zones or on higher ground near the city center where the flood waters did not reach. Finally, Figure 7 shows the range of Hurricane Katrina's storm surge along the Mississippi coast and the varying degrees of damage suffered by libraries in the region. With the exception of the libraries in Hattiesburg and the library that was eventually closed substantially inland in Shubuta, northeast of Hattiesburg, the high occurrence of yellow and red color code symbols (moderate and severe damage) clearly demonstrate the path of destruction by the storm. As can be seen, the surge extended substantially inland and across the low-lying counties. As a result many of the libraries on the coast were inundated and suffered heavy damage. 


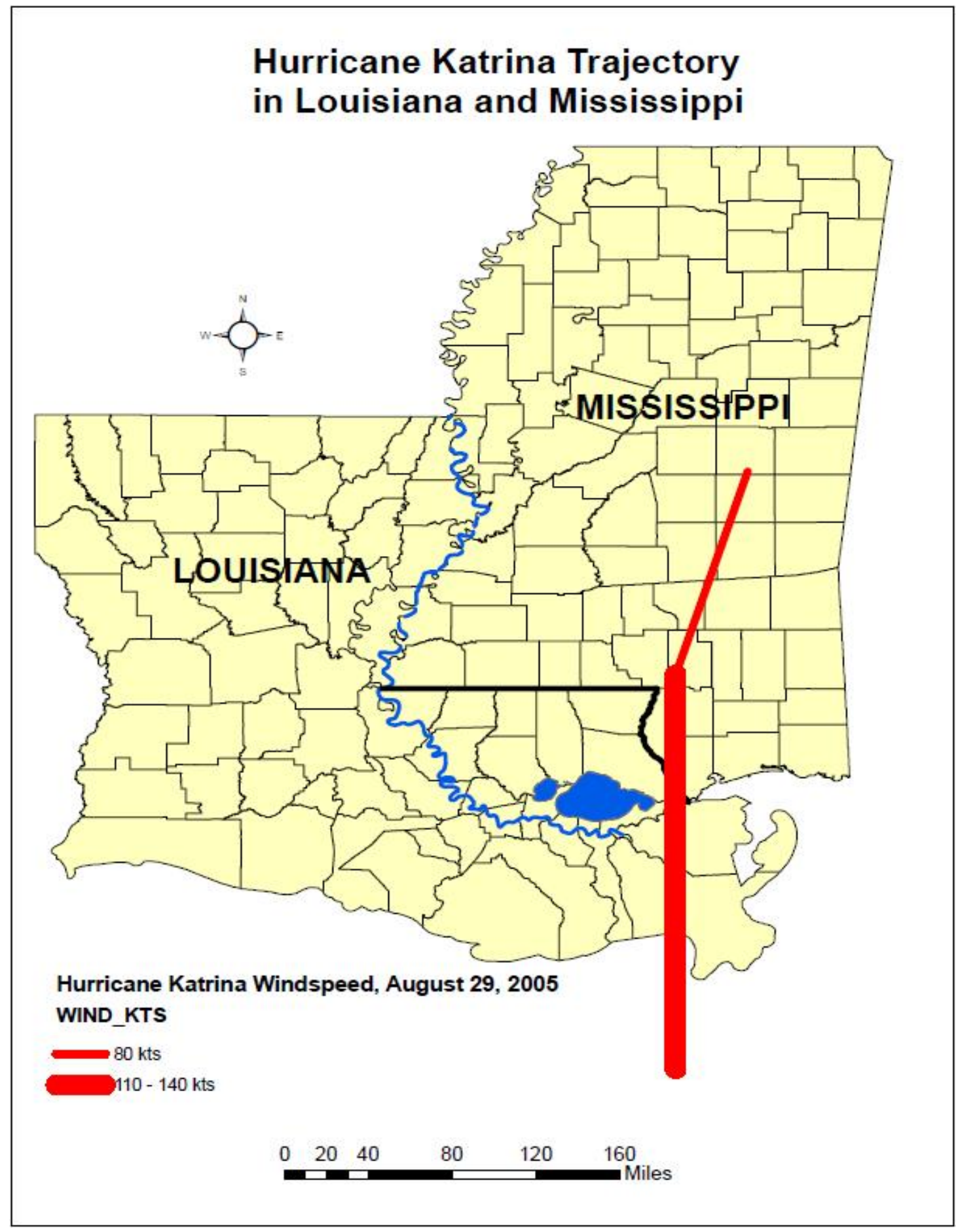

Figure 4. Hurricane Katrina trajectory and wind speed (in knots), Monday, August 29, 2005. Note how the thickness of the line representing the storm's trajectory thins substantially after losing strength over land. New Orleans lies beneath the southeastern side of the large body of water (Lake Pontchartrain). 


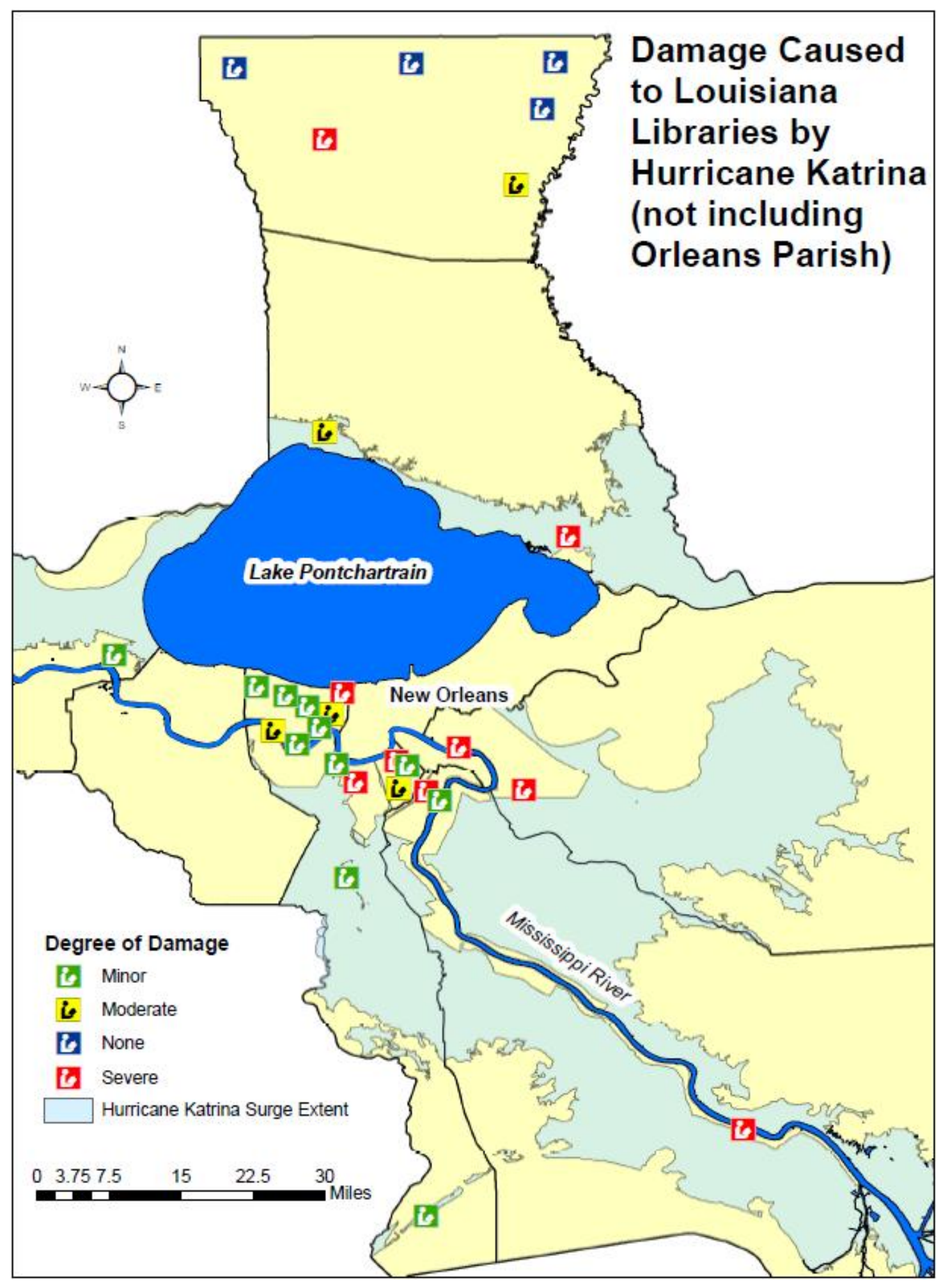

Figure 5. Location and severity of damaged libraries in southeastern Louisiana (excluding New Orleans). Each icon represents a library. Note extent of storm surge. 


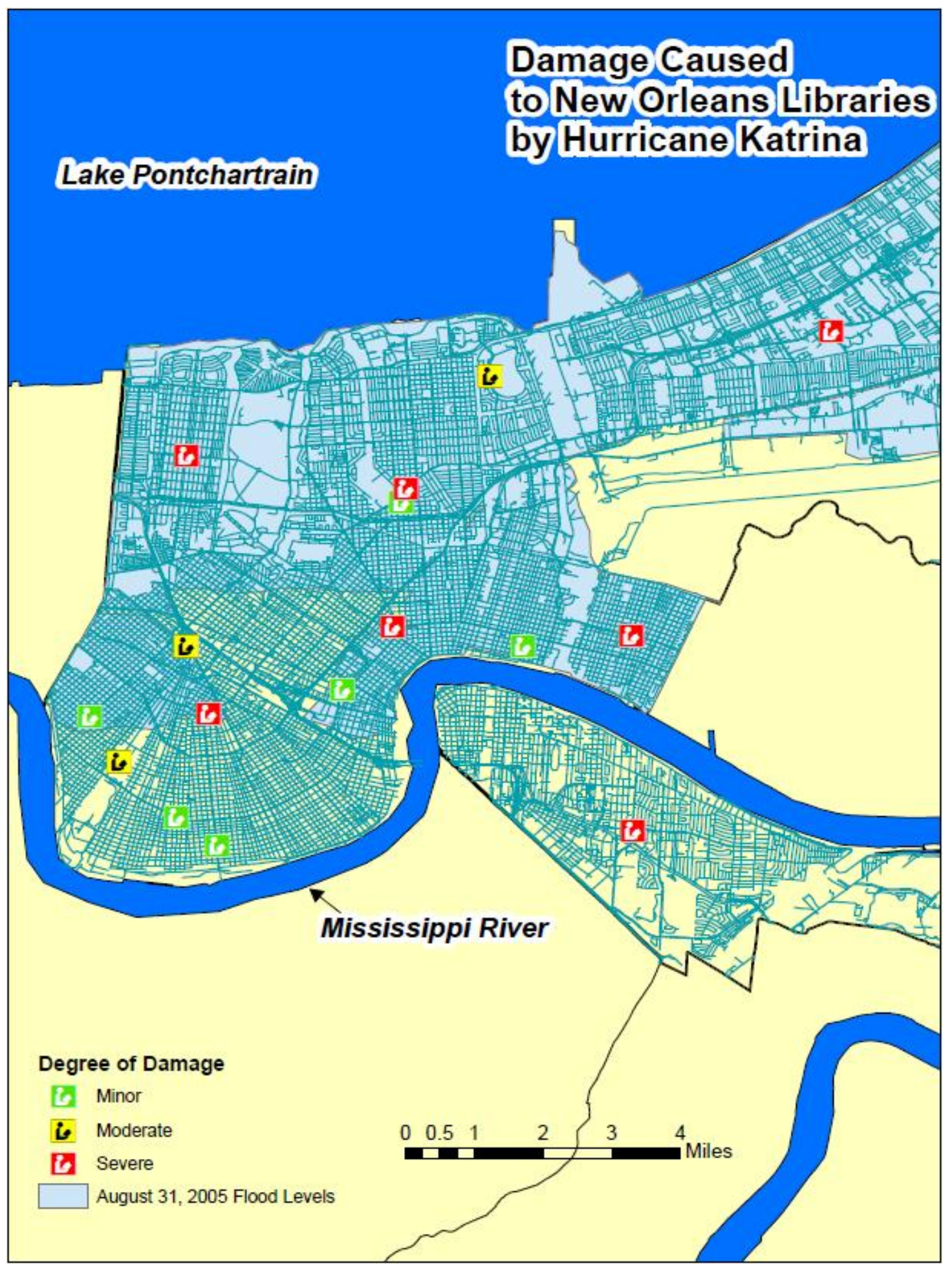

Figure 6. Location and severity of damaged New Orleans libraries. Each icon represents a library. Note extent of flooding. 


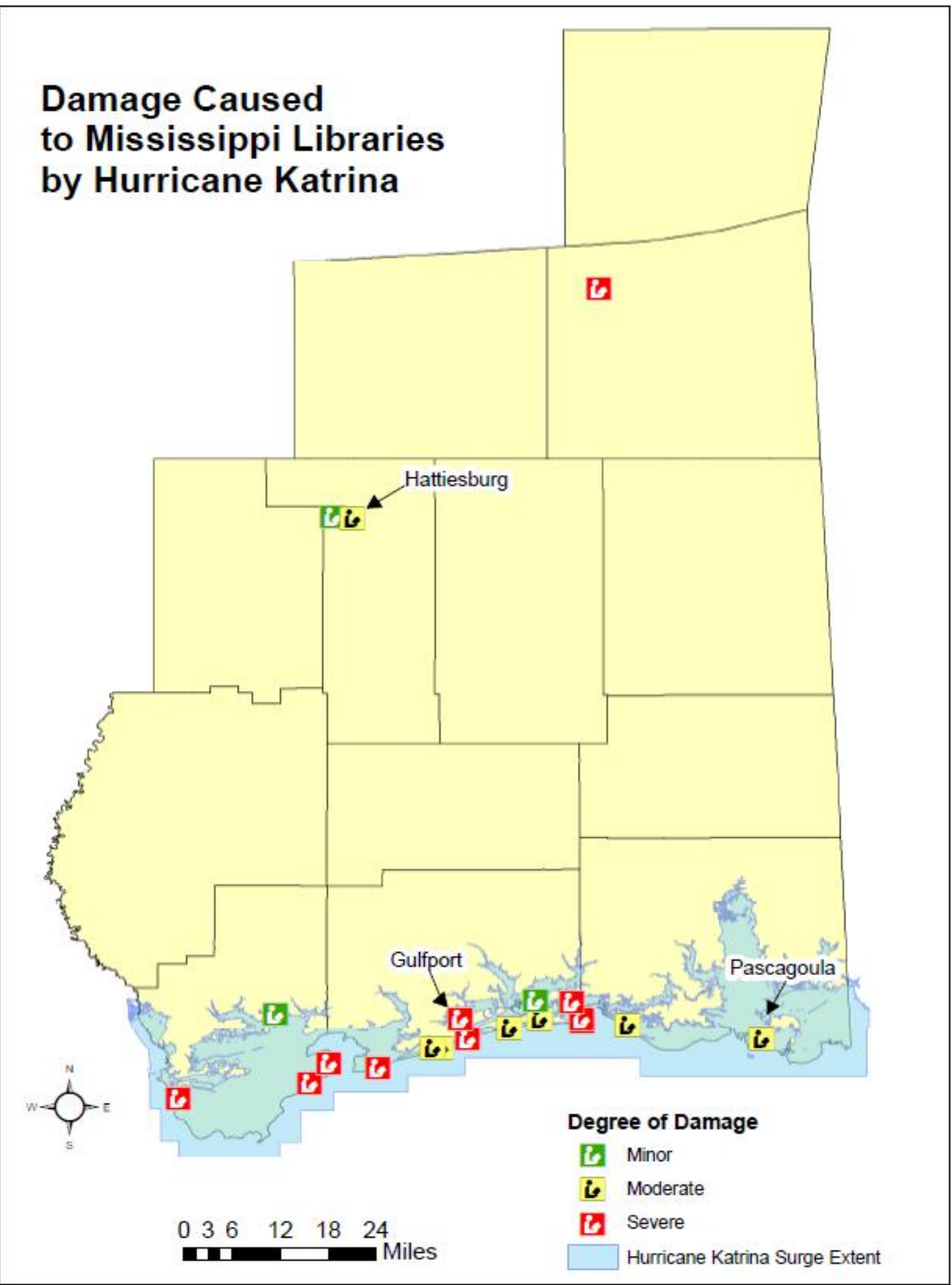

Figure 7. Location and severity of damaged Mississippi libraries. Each icon represents a library. Note extent of storm surge. 
The damage that libraries in Louisiana and Mississippi experienced during and after Hurricane Katrina was astounding and nearly complete. While damage was caused both by the storm's high winds and flooding, the most severe damage was as a result of storm surge and subsequent mold. Needless to say, libraries receiving the greatest damage were those located close to water sources, such as those along the Mississippi coast and in lowlying areas in Louisiana. The damage discussed in this chapter was present in very general terms, based on the data available. The case studies in the next chapter provide a more nuanced description of the hurricane's impact on specific libraries, based on the experiences of information professionals working in those institutions. 


\section{Chapter 5: Gulf Coast Libraries Case Studies}

This thesis has focused on the extent of damage caused by Hurricane Katrina in the Gulf Coast community and its libraries. The previous chapter identified damage to the region's libraries and provided an overview of the levels of damage experienced during and after the storm. While some of the damage was caused by the storm's winds, most destruction was caused by the storm surge and resulting flooding. The specific examples showed just how vulnerable the libraries in this region are.

Another factor contributing to how much libraries and their collections suffered during the hurricane was whether disaster mitigation plans were present and implemented prior to its landfall. These library disaster plans typically are designed with small, local issues in mind, such as water pipes bursting or a small fire. A glimpse into past library disasters has shown how effective at safeguarding a library's collection and staff such plans can be. During many of these incidents, only part of the library's collections was affected. However, a region-wide catastrophe such as an earthquake or hurricane, especially one the size of Hurricane Katrina, is an entirely different story. In such an event, the potential for greater damage is magnified throughout the entirety of the library. Also, the surrounding community upon which libraries rely for required resources such as electricity, running water, and emergency services is also greatly impacted during a region-wide disaster like a hurricane. Therefore, when libraries in the path of a major hurricane like Katrina experience power failures, catastrophic flooding, and mold outbreaks that threaten their collections, it is much more difficult for them to get the 
assistance they need. In order to more closely examine how well or how poorly Gulf Coast libraries fared before, during, and after Hurricane Katrina, it was determined that it would be both beneficial and necessary for this research to send a questionnaire to Gulf Coast library professionals whose institutions were hit by the hurricane. The institutions surveyed included academic, public, and governmental depository libraries in southern Louisiana and southern Mississippi; they were chosen so as to provide a representative sample of Gulf Coast libraries and their experiences with Hurricane Katrina. The two libraries in Louisiana are located in metropolitan New Orleans, while those in Mississippi are located along the Mississippi coast. The two libraries in Louisiana include one academic library and one governmental depository library. The two libraries in Mississippi consist of another academic library and one public library. The respondents' answers to this survey provided information about both the damage from Hurricane Katrina and their library's disaster preparedness at the time of the storm. Finally, the answers provide valuable insight to the state of disaster preparedness at libraries in vulnerable areas.

\section{Survey Methodology}

The areas covered in this section include the selection of the respondents, the construction of the survey and the purpose of each question, the procedure for distributing the survey and collecting the responses, and the reporting of the results. The methodology was approved by San José State University's Human Subjects-Institutional Review Board on November 10, 2009. 
The purpose of the survey was to obtain in-depth insight into each respondent's experiences before, during, and after Hurricane Katrina to learn about the damage sustained by their libraries and to learn how well or how poorly their existing disaster plans helped mitigate the damages at each institution. The survey consisted of eight questions which, taken together, collected data regarding library damage and the role the disaster plan played in responding to the storm (see Appendix A for complete survey form).

The first question sought to find the degree of damage each library received as a result of the hurricane and ensuing flooding. The second question meant to discover the dollar amount of the damages the libraries sustained. Question three attempted to determine where the most damage to the libraries occurred. The fourth question further fleshed out the damage aspect by inquiring of the respondents whether there were any pre-existing factors prior to the storm that may have contributed to the damage sustained to their collections by the storm. The fifth question asked if a disaster plan was in place at the institution at the time of Hurricane Katrina's landfall. The sixth question meant to gauge how well or inadequately the implemented disaster plan worked during and after the hurricane. Question seven inquired about the library's current disaster preparedness policy and whether it was revised in light of the Hurricane Katrina experience. Finally, since each respondent's institution experienced damage, the eighth question asked how the rebuilding process of their library has fared since Hurricane Katrina, as well as how the disaster affected the relationship between their libraries and its patrons. 
Because the libraries discussed throughout this thesis are public, academic, and government depositories, it was determined that one representative of each type of library would be contacted to discuss the damage at their library caused by Hurricane Katrina. In addition, the choice of which library professionals (respondents) was based on their visibility in the library literature post-Katrina. In the end, four respondents representing different types of libraries throughout Louisiana and Mississippi agreed to participate in the survey: two academic librarians, one from the Mississippi coast (Library A) and the other in New Orleans (Library B); one public librarian from the Mississippi coast (Library C); and one government depository librarian in New Orleans (Library D). In the following section, all of the responses for each question shared by each of these respondents are discussed in this order.

After compiling a list of potential respondents, each librarian was sent an email with a consent form that described the purpose of the survey. Each respondent was asked to read this consent form and reply by email indicating whether they would participate in the survey. Those who replied that they would participate were then emailed a copy of the survey as a Microsoft Word attachment with directions for completion. The respondents were advised to save a copy of the survey to their computers and type their answers directly into the document for easier data extraction later. They were instructed to include their name, the institution with which they are affiliated, and their professional title. Also, they were encouraged to be as detailed as possible in their responses. Finally, they were asked to submit via email their completed survey by March 15, 2010. 
Once all of the respondents submitted the completed surveys, each of their answers were summarized for inclusion in the following section, Survey Results. In addition, two of the respondents included current disaster plans for their libraries for further insight. Finally, the identities of the respondents, their libraries, and affiliated institutions were kept confidential. Only the type of library represented and its geographic location are identified below.

\section{Survey Results}

The survey's in-depth look at four representative libraries provided valuable insight into how the Gulf Coast library community suffered from Hurricane Katrina. It showed that one type of library did not necessarily fare better or worse than another type of library, with damage being indiscriminate. The survey made it clear that most of the damage that libraries sustained was due to flooding brought about by the storm surge. Not surprisingly, most of the libraries' losses were on the lower floors since these areas

are most susceptible to flooding. The survey also showed that regardless of how detailed and well-rehearsed existing disaster plans may have been, it did not appear to make a noticeable difference in regard to collection or building preservation.

According to the testimony of the respondents, the disaster appears to have had several positive outcomes. For example, the library-patron relationship seems to have improved at the libraries affected, with the staff projected as being much more involved and proactive with their communities via library programs. In one respondent's answer, the many patrons who came to the library during the recovery period seemed to have 
bonded with the library staff. Also, the Hurricane Katrina disaster allowed these respondents to become more aware of their institutions' disaster plans by realizing the need to become more familiar with them and where improvements could be made for the future. A detailed look at all of the respondents' answers will provide better understanding of the ordeal they faced and the role disaster plans played.

- Question 1- Generally speaking, what types of damage did your library/archives sustain during and after Hurricane Katrina?

This question sought to address the degree of damage each institution received as a result of the hurricane and ensuing flooding. Because all of the respondents' libraries are located at or near sea level along the Gulf Coast, all of the respondents indicated, not surprisingly, that most of the damage occurred as a result of flooding.

The respondent from the first of the two academic libraries along the Mississippi coast (Library A) explained that the building that houses the main library on the first floor lies 21 feet ( $6.5 \mathrm{~m}$ ) above sea level. However, due to the massive storm surge, the library was flooded by about one and a half feet $(46 \mathrm{~cm})$ of water originating from the marsh that lies behind the building and came in through the door vents and under the doors. The respondent goes on to say that there was nearly three feet $(1 \mathrm{~m})$ of water in the first floor hallway of the building. This discrepancy in flood height was not explained by the respondent, though it seems likely that the library's closed doors kept a substantial amount of the water contained in this one area, explaining the lower height of floodwater in the rest of the library. 
The respondent representing the second academic library located in metropolitan New Orleans (Library B) explained that the bottom floor of the library was flooded to a depth of two feet $(61 \mathrm{~cm})$. Though only about 100 books and one piece of computer equipment were destroyed, the respondent reported that the entire floor had to be gutted due to the extensive outbreak of mold. This required repairs to the existing electrical system, new sheetrock, and floor covering installations. The respondent goes on to relate that due to early intervention mold did not extend into the upper floors of the building and that there was no other damage.

The respondent representing the public library along the Mississippi coast (Library C) reported that one wing of the public library had approximately three to four feet (1 to $1.2 \mathrm{~m}$ ) of water due to the storm surge. This inundation was the result of broken windows and roof damage. After the storm, a period of very hot, humid weather precipitated a mold outbreak throughout the library. The subject also reported that debris, pests, pine straw, and sewage filled the first floor of the library.

The respondent representing the government depository library in metropolitan New Orleans (Library D) reported on the status of three of its libraries. Two libraries are located at the institution's main campus, while a third library is housed at the institution's other campus located downtown. It was reported that there was major damage to the two library buildings on the main campus and some minor damage at the downtown campus. At one of the library buildings on the main campus, there was eight feet $(2.4 \mathrm{~m})$ of water in the basement, specifically in the Music Library. This respondent also indicated that in 
this library a variety of government documents, microforms, and holding stacks for noncatalogued materials were underwater. In addition, he goes on to say, there was much destruction to the public area and library offices including computers, listening stations, and staff equipment. At the second library building on the main campus, there was four feet $(1.2 \mathrm{~m})$ of water in an area that housed archival materials. At the downtown campus, the library facility only sustained damage to the computer lab, and no library materials were damaged.

All of the respondents reported a variety of damage caused by Hurricane Katrina. While some wind damage was reported, the most serious damage was caused by flooding. The lowest floors of these libraries sustained the most flood damage. Later, mold outbreaks as a result of the ensuing weeks of hot weather were reported at these locations. After the storm, in at least one of the libraries debris and pests were found which also contributed to the damage.

- Question 2- What was the total dollar amount of disaster-related casualty losses to the building, contents, and collections? Please provide a breakdown of the losses if available.

This question was asked in order to discover the dollar amount of the damage the libraries sustained. Most of the answers were not specific due to either a lack of knowledge or an inability to divulge this information because of continuing legal procedures. For those who did provide figures, the dollar amount for damages sustained ranged substantially. 
The respondent representing one of the academic libraries gave very detailed figures regarding losses. The respondent estimated damage to be upwards of $\$ 100,000$. Lost were 1255 books (not including those in circulation to offices and homes which were also flooded or destroyed), all or parts of 134 serial titles, and 2966 pieces from a combination of reprints, grey literature ${ }^{5}$, and technical reports. The respondent goes on to say that all office furniture was lost, as well as 14 four-drawer filing cabinets, several map cabinets, a sofa, two chairs, a coffee table, a photocopy machine, four glass-fronted locking cabinets, the circulation desk, and cabinetry. In addition, the flooring had to be replaced, the walls repainted, and the shelving treated and painted.

The respondent representing the other academic library was never told the exact cost of damages from the storm and flooding. He does indicate, however, that $\$ 100,000$ was spent to protect the facility's Archives and Special Collections from a mold infestation following the event. No further details on what action this dollar amount involved.

The respondent from the public library did not share the dollar amount of the damages sustained, nor indicate why.

For the governmental/archival library, the respondent shared that the institution is still in litigation with insurance firms over the losses sustained and cannot divulge any specific figures. However, the respondent stated that the cost of the damages is roughly $\$ 80$ million.

\footnotetext{
${ }^{5}$ Grey literature is any documentary material not commercially published, usually composed of technical reports, working papers, business documents, and conference proceedings (Mathews, 2004).
} 
For those figures provided, the cost of the damages sustained at these libraries was substantial. The range of damage was $\$ 100,000$ at the academic libraries to an estimated $\$ 80$ million at the governmental depository. It appears that the damages to the second academic library (Library B) were likely more than the $\$ 100,000$ cited. The amount of damages cited by the governmental depository library seems excessive, though that library had multiple buildings damaged by Hurricane Katrina. It is worth noting that most of the respondents were only able to provide approximate damage costs or none at all, as in the case of the public library.

- Question 3- Where was damage to your institution the heaviest (i.e., basement holdings, first floor, exterior structure, etc.)? Please be specific.

This question was asked of the respondents to discover in what area(s) of their libraries the most damage occurred. The respondents' answers to this question indicated the heaviest damage was sustained in the first floor and basements, which is where their collections were located. That library collections were located in the lowest areas of the building is surprising given the region's vulnerability to flooding.

The one academic library in Mississippi is located on the first floor of a laboratory building situated on the north side of the campus, overlooking a bayou and adjacent marshland. The respondent indicated that because of this location, the library received flood waters, with all offices, work areas, and collection areas affected. Across the entire campus, losses included three classrooms/labs, half of the Toxicology Building, greenhouses and grow out tanks, and a small fisheries building with labs and offices. All 
but one building flooded and those buildings closest to the Mississippi Sound were lost or damaged.

The respondent representing the other academic library reported that only the first floor of the library was affected. That floor was flooded to a depth of two feet $(61 \mathrm{~cm})$ and later experienced a significant mold outbreak. As a result of the mold, the entire floor was later gutted and remodeled.

At the public library, the respondent indicated that because buildings along the Gulf Coast typically do not have basements, the first floor of the library building experienced the heaviest damage. It was also noted that for this same reason other county library system branch locations along the Mississippi coast sustained serious damage to their first floors, as well.

The respondent for the governmental depository library explained that just about all of the losses were sustained in the basement of the main library. However, the respondent did not provide more detail about these losses. The respondent also indicated that there was much less loss in the archival area of the second campus library facility located across the street from the main library, though the reasons were not discussed.

This respondent did provide some detail about recovery efforts. It was noted that the efforts made to identify the most valuable classes of materials for restoration, given the deplorable conditions of the salvage operations, consisted of searching through dark flood waters, with no electricity and very warm temperatures. Recovery efforts were reported to have been successful. Nearly $70 \%$ of the monographs in the Music Library, which is housed in the main library building on campus, were freeze dried, cleaned, and 
restored. Similar success was reported with saving the microfilm collection of the rare Mexican newspapers. However, the respondent said no efforts were made to save the microfiche.

Not surprisingly, the heaviest damage to the four libraries was caused by flooding. All of the respondents indicated that the damage was most severe on their library's first floor and basement. Also, two of the respondents hinted that the libraries' locations new water sources played a role in the amount of damage received.

- Question 4- Were there pre-existing factors that contributed to the level and nature of damage to your facility and/or collections? If so, please elaborate.

This question was asked to further explore the extent of damage to the libraries by inquiring of the respondents if they were aware of any pre-existing factors prior to Hurricane Katrina that they felt may have contributed to the damage sustained to their collections. The respondents cited a number of factors that contributed to the damage their libraries received, including the physical locations of buildings, locations of collections within buildings, and locations of plumbing and access fixtures in proximity to collections.

The respondent from one of the academic libraries acknowledged the vulnerability of the library's building due to its location. As noted above, this library is housed in the university's marine biological research station, which is on the shore of the Mississippi Sound. The respondent explains that while the building that houses the library is not on 
the sound side of the campus, it is directly south of both a bayou and marsh. As a result, the low elevation of this waterlogged area, augmented by the storm surge and rains of the hurricane, was the source of the flooding.

The respondent for the other academic library indicated that because the library is located on a slight elevation and somewhat higher than other buildings, the degree of damage was less than what other campus buildings endured. This is reflected in the relatively minor damage sustained in the ground floor of the library, which was flooded only to a depth of two feet $(61 \mathrm{~cm})$.

The respondent from the public library indicated that prior to the arrival of Hurricane Katrina plans were underway for moving the department to the second floor of the building they were sharing with the local art museum. However, due to timing issues, this move was not accomplished before the storm's landfall. The respondent speculated that had this move to the second floor been accomplished, the damage likely would not have been as bad since the second floor fared better than the first after the storm.

The respondent from the government depository reflected that the decision to store library materials in the basements of two campus library buildings was ill-advised. Basement storage of collections put them below sea level in an area notorious for flooding. Other pre-existing factors that contributed to the degree of damage were an external doorway opening into the basement (it was not specified at which location), elevator shafts, and toilets and plumbing without shut-off valves to prevent the backup of water from the city sewage system. 
All of the respondents shed light on the pre-existing conditions that may have impacted the damage sustained at each library. Also, this question focused attention on the issue of library location risks. The building housing one of the academic libraries was located near a substantial body of water, as well as being in close proximity to a boggy area. Another respondent questioned the decision to place library collections in not only the basements of two buildings, but near building access points and water sources that posed a threat to their safety. The public library respondent lamented bad timing as a factor for the damage suffered there. One respondent, however, positively noted that the location of the building that housed the library was slightly elevated and likely prevented further flooding.

- Question 5- What was the disaster plan you had in place for your library/archives prior to Hurricane Katrina? Were any drills or mock disasters ever conducted? Please elaborate and include any written policy.

This question was asked to see if any of the libraries had a disaster plan in place at the time of Hurricane Katrina's landfall. Because of hindsight, the librarians' responses were honest and informative as they shared their plans' inadequacies, particularly in terms of their libraries' known vulnerability being located at or close to sea level. Two of the respondents also provided copies of their most recent disaster plans.

The respondent from one of the academic libraries indicated that the library did not - and does not—have its own hurricane preparedness plan because it is part of a 
larger research facility. Although the library does have a disaster plan (which is part of the research facility's plan), unfortunately, according to the respondent, it did not include procedures for flooding, as the building had not flooded since its construction in 1971 and no previous hurricane had such a significant storm surge.

For the other academic library, the respondent provided some interesting insight into this question by sharing a personal belief that no one in the city of New Orleans likely had much of a disaster plan in place since it was generally understood that if the levees breached, the flooding would be massive, thus rendering such a plan useless. The respondent further stated that the institution had an emergency website in place to keep people informed during the crisis, but that little existed beyond that. Finally, the respondent said that before Hurricane Katrina there neither drills, nor mock disaster simulations conducted at the library, and that none have been done since.

The respondent for the public library said that there was a system-wide emergency plan in place, though it was more general in nature, dealing with closures and employee issues rather than with protecting library materials. The respondent goes on to say that prior to Hurricane Katrina the disaster plan's instructions for the department were only communicated verbally. However, it included such actions as moving collections and equipment away from windows, covering materials with plastic sheeting in the event of a compromised roof, and moving special materials to the second floor or other buildings. After the storm, the respondent created a written disaster plan for the department, and it has been utilized on several occasions since. Finally, it was communicated that the department staff is aware of and has access to this plan, which 
includes instructions for a variety of emergency situations. This respondent included a copy of the latest disaster plan.

The government depository respondent stated that the library had a disaster plan that has since been upgraded and updated. The respondent goes on to say that the only drills conducted were annual or semi-annual fire drills. This respondent also included a copy of the latest version of the disaster plan, but did not have access to the version of the plan as it existed prior to Hurricane Katrina.

All of the respondents provided valuable insight to how their libraries planned to cope with threats to their collections by way of disaster plans. All of these library locations could be considered as being at risk since they lay in New Orleans and along the Mississippi coast. It is worth noting that two of the libraries seemed to not have official plans ready at the time of Hurricane Katrina. Also, the library with the disaster plan that did not address the threat of flooding prior to the hurricane is the one that is arguably the most vulnerable.

- Question 6- What parts of the disaster plan worked and what parts need revision? Can you explain why or why not?

This question was meant to gauge how well or inadequately the implemented disaster plans worked for the respondents' libraries during and after Hurricane Katrina. Some of the respondents bemoaned their inability to realistically address anything more than local 
issues, such as burst water pipes. The overall impression is that the respondents were aware that these plans were not able to mitigate an event the scope of a hurricane.

The respondent for the first academic library said that the policy for the institution was designed to deal with winds and broken windows as a result of a hurricane, but it did not include storm surge. The respondent indicated that in preparation for future disasters involving storm surge, the physical plant will be responsible for sandbagging the doors of the building where the library is housed. This provision has since been incorporated into the current disaster plan.

The respondent for the second academic library did not address this question. It is implied in the respondent's previous answer that a real, working disaster plan was not in effect at the institution at the time of the disaster. It is also stated by this respondent that the institution did not have much beyond an emergency website to keep people informed during the crisis.

The respondent for the public library replied that a major weakness with the preKatrina version of their plan was that it was not written down beforehand. This caused problems for the respondent on the Saturday before the storm made landfall when trying to prioritize collections "on the fly" as well as being responsible for moving them to safer ground alone. A particular problem encountered was dealing with moving library materials to the city hall's vault, located across the street from the library. When the respondent, along with the rest of the Gulf Coast, realized that the storm was going to be a major threat to the region the Saturday before it made landfall the following Monday, the city hall was closed. This rendered that part of the unwritten disaster plan null and 
that location inaccessible. Putting a positive spin on the experience, this respondent said one of the best things learned as a result of the hurricane was to be adaptable in disaster planning.

The respondent for the government depository library admitted that the disaster plan that existed pre-Katrina was "worthless". While addressing relatively minor incidents such as broken water pipes and small fires, the plan simply did not provide an adequate remedy for a disaster the magnitude of Hurricane Katrina. Since then, one of the major revisions was the addition of a provision for bringing in disaster recovery specialists. The respondent did not clarify whether these specialists were to be consulted for plan development or brought in as part of the recovery process post-future disaster. The new plan also provides for more complete and sophisticated communications for locating library staff. During Hurricane Katrina, regional cell phone towers were knocked down, causing cell phones to be rendered unusable as a means of communication. The old plan did not address this as a possibility due to not anticipating downed cell phone towers or staff seeking safety in other parts of the country. This provision in the plan minimizes the possibility of leaving library personnel unaccounted for. The new plan also provides for more complete communication between the library and other university departments. An important part of this new communication directive is a hurricane evacuation survey form that lists all university employees' contact information. Department heads have a copy of this contact list so they can communicate with employees during and after a disaster. Finally, the revised disaster plan also outlines communication policy between the library and university with FEMA before, during, and after the disaster. 
Most of the respondents' answers to this question illuminated issues associated with disasters the scope of Hurricane Katrina. Most provided examples that showed the inadequacies and shortcomings of disaster plans when confronted with crises larger than a leaking water pipe or small localized fire. Having a written disaster plan that is known by the staff is more helpful than one that is known only verbally, as in the case of the public library respondent. These respondents also included positive examples of improvements to their current disaster plans made as a result of their experiences during Katrina.

- Question 7- What is your current disaster preparedness policy? Can you expand on how this policy differs from what may have existed pre-Katrina?

For this question, the purpose was to glean from the respondents if any additional disaster preparedness measures had been implemented as a result of Hurricane Katrina. With all respondents reporting different degrees of damage, it was expected that there would be acknowledgements of changes to existing policies.

The first academic library respondent said that the policy has been revised to include moving books up one shelf wherever possible and sandbagging the building's entry points. The respondent goes on to say that these additions to the policy were implemented for Hurricanes Gustav (2008) and Ike (2008). However, neither hurricane made landfall near the campus. 
The respondent for the other academic library commented that the only change that is foreseen is to have a more rapid closure and evacuation of the campus when future storms threaten the city. The respondent added that they experienced another close call during the previous summer, but luckily no one was trapped on the campus, which was what happened during Hurricane Katrina.

The public library respondent said the biggest difference between the disaster policy pre- and post-Katrina is that the library now has a written policy. This policy has been approved by the respondent's direct supervisor, system director, and library board. The respondent also made the important point that while the policy currently in use is general in nature, every disaster is unique and room is needed to adapt the policy to the disaster at hand. Finally, the respondent has realized the importance of having disaster supplies readily available.

The respondent for the government depository library stated that in regard to the institution's current policy, the major points of difference are explained in the answer to the previous question (e.g., addition of provision to bring in disaster recovery specialists, more comprehensive communication among library and university departments, and directives regarding communication with FEMA).

A couple of the respondents provided answers to the previous question that belonged more to this one when detailing differences in their institutions' disaster policies pre- and post-Katrina. However, some further information was provided, such as sandbagging doors and shifting books. Also, the hope for a more rapid closure and evacuation of the 
campus was expressed by several respondents. Finally, in one instance, the disaster policy is now in written form.

- Question 8- How has Hurricane Katrina impacted the rebuilding of your facility and collections/archives? How has it affected the employee-patron relationship?

This final question was asked so the respondents could share how they felt the rebuilding process of their libraries and relationship with their patrons has been impacted by Hurricane Katrina. All replied that these relationships appear to have been greatly strengthened and that their libraries have recovered since the disaster.

One of the academic library respondents commented that the library has received numerous recovery funds and reimbursements from FEMA, the Mellon Foundation, and the Rotary International Zones $29 \& 30$. The respondent also praised the volunteer assistance provided by the library's patrons during the recovery process. Ending on a positive note, the following observation was imparted: "If you ever experience a terrible disaster, you will find that good people pull together to help and support each other."

The second academic library respondent related that the campus library was the first building back in service post-Hurricane Katrina primarily because of the limited damage to the facility. However, it was added that little has been done to the building since. In regard to collections, the respondent stated that the library has invested and continues to invest in more electronic books and journals so they can be accessed by university faculty 
and students from off-campus. Insight into the library's relations with its patrons was not provided.

At another affected location, the public library respondent stated that as a result of Hurricane Katrina, there are four building projects currently underway in that county's public library system. The respondent goes on to say that this is as a result of the hurricane and associated flooding that severely damaged all of the library system's main library locations, including the headquarters. The respondent did not discuss how the disaster may have impacted the library employee-patron relationship.

The respondent from the government depository library provided the most detail in regard to how progress has been made at the university and library since the disaster. The rebuilding of the main library has been delayed by FEMA. Funding of the construction for two additional floors at the main campus library and the remediation of the basement of the other campus library was not approved until 2009. While the respondent cannot provide the details of what kinds of delays the institution has been experiencing due to legal constraints, an example was provided showing the use of temporary, mobile heating, ventilation, and air conditioning (HVAC) units, designed to last one year, that are now entering their fifth year of usage. Plans for permanent HVAC units are to be designed for installation on the roof rather than in the basement. Library materials are no longer allowed to be housed in the basement, as well. One positive result of the disaster is that the respondent's institution now possesses one of the most complete digital collections in North America. In fact, the respondent noted that the 
library has developed a much stronger collection from the faculty and students' perspectives, though the respondent did not provide detail on this perception. The respondent goes on to say that the institution appears to have become more selective of its students after Hurricane Katrina and, perhaps as a result of their experience during and after Katrina, these students seem more serious and dedicated. While the disaster presented the respondent's institution with many challenges that threatened its existence, it forced the university to reassess its programs. What resulted was a university-wide plan that reorganized its existing academic structure that placed emphasis on science curriculums as well as encouraged the development of new initiatives. Because of this plan, university recruitment of faculty and students is currently at an all-time high. Finally, the respondent seems to believe that the relationship between library staff and patrons was strengthened after Hurricane Katrina as a result of the university's recruitment of more dedicated students.

\section{Discussion}

This chapter was intended to provide a cross-section of the Gulf Coast library community's experiences with Hurricane Katrina and afford the opportunity to see how well their disaster plans worked in action. While the professional library literature has provided a substantial offering of sad tales recounting the destruction sustained by Gulf Coast libraries during and after the hurricane, it failed to mention the roles disaster plans may have played in the preservation of these libraries and their collections. Therefore, it was imperative for this research to obtain the personal perspective of Gulf Coast library 
professionals. The feedback of these respondents is valuable to ongoing research on disaster planning for all libraries, but especially ones in obviously vulnerable areas.

After analyzing the library respondents' experiences, there appear to be two factors that impact the effectiveness of disaster plans for Gulf Coast libraries: the library's location and the scope of the disaster. A library's physical location plays a significant role in the safety of its collection. As the first part of this survey illustrated, the amount of damage suffered by the representative libraries during and after Hurricane Katrina was in large part due to where the libraries were located. On a positive note, the academic library respondent from New Orleans observed that the slight elevation of the building in which the library was housed likely resulted in less flood water entering the library than in other lower-lying buildings. However, its location on the first floor of a building in a city notorious for flooding still translated into flood damage. One respondent reported that the libraries were located in the basements of two campus buildings, resulting in significant floodwater levels. The remaining two respondents indicated library collections existing on the first floors of buildings. One of these libraries is located in a building that is situated between Mississippi Sound and low-lying marshland. They likely are not the only libraries in such compromising locations. Considering that much of the elevation of the Gulf Coast region lays at or near sea level, the location of the libraries represented here invited the kind of disaster that any standard disaster plan would have great difficulty preventing or mitigating. 
Another issue affecting a library's disaster plan is the scope of the disaster. To paraphrase one of the respondents, disaster plans are intended to mitigate local disasters, such as a leaking pipe, a small fire, or even a power outage that could affect the climate control of a collection. However, part of a plan's chance for success is that it assumes there are personnel and resources immediately or nearly immediately available to effectively deal with and remedy the mishap. What are the ramifications of a disaster that can affect entire regions like a hurricane, earthquake, or tornado? Not only is a disaster of this size capable of destroying a particular library's collection and physical structure, it can and does easily cripple the support system a library relies upon for mitigation. Thus, one possible viewpoint is that a collection is only as safe as the scope of the disaster and the accessibility of the resources librarians rely upon to help mitigate the resulting damage. During Hurricane Katrina, many systems and resources throughout the region were compromised. Those still intact were overloaded responding to more immediate needs, such as providing shelter for victims, maintaining order during evacuation, restoring order after the disaster had passed, putting out fires caused by gas explosions, and actively saving people from floodwaters. Systems of support in the devastated Gulf Coast region after Hurricane Katrina were nearly incapacitated at the local and state levels, and only barely functioned as a result of federal and military interaction.

Another important issue brought out by the survey are the types of "disasters" most disaster plans address. Typically, disaster plans focus on events happening singly, not a succession of events that are likely to happen during a hurricane or earthquake. In all of the examples shared by the respondents, it was not a solitary event, but rather several that 
caused the damage to the libraries. Each institution experienced multiple levels of damage: power outages affecting climate control, water damage brought about by floodwaters and rain water, and mold outbreaks. To again paraphrase one of the respondents, no disaster plan can anticipate a disaster the magnitude of Hurricane Katrina.

The answers to this survey by the respondents shed significant light not only on the damage wrought by Hurricane Katrina on these libraries, but how successfully their respective disaster plans performed as well. Their answers also revealed factors not considered in the libraries' disaster plans and changes in those plans that have been made since. Fortunately, the libraries represented here seem to have responded positively to Hurricane Katrina, and generally the librarians feel that their libraries' collections and relationship with patrons have improved as a result. 


\section{Chapter 6: Conclusion}

The goal of this research was to examine the experiences of Gulf Coast libraries during and after Hurricane Katrina and to assess how well their disaster plans-for those that had one-mitigated the damage. More specifically, it was desired to learn whether existing disaster plans adequately safeguarded libraries and their collections. There were several research questions framing this study. One goal of the research sought to learn what pre-existing factors may have led to the level of destruction by Hurricane Katrina to metropolitan New Orleans, southeastern Louisiana, and southern Mississippi libraries. Another goal was to discover the types of damage these libraries sustained and why. A third research goal was to find what disaster plans were in place at a select number of Gulf Coast libraries because of their vulnerability to hurricanes. Related to this was another goal to discover what disaster preparation may have taken place at these libraries since Hurricane Katrina. A final objective was to find what lessons were learned as a result of this disaster. Chapter 1 familiarized the reader with the intent of this research, and outlined what was involved and how it would proceed in subsequent chapters. Chapter 2 discovered several gaps in disaster preparation prior to Katrina that exacerbated the disaster, particularly natural and man-made flood protection inadequacies and communication issues among government and emergency management officials. Chapter 3 illustrated how the shortcomings in disaster preparation and communication discussed in chapter 2 contributed to the severity of the disaster throughout southeastern Louisiana and southern Mississippi. Chapter 4 showed how Hurricane Katrina generally impacted libraries in the region, especially the flooding that occurred because of the 
storm surge. Finally, chapter 5 showed how a library's location and the scale of a disaster can impact the effectiveness of a library's disaster plan.

This chapter is organized into four parts. The first part of the conclusion will look at several large-scale library disasters around the world. The second part will then look at the effectiveness of disaster plans for libraries involved in these disasters. The third part will bring up common themes similar to the large-scale disasters affecting these libraries and those represented by the survey from chapter 5 . The last part will reflect upon the research and findings, as well as provide some final suggestions for what library personnel can do to better prepare for future disasters that are the scale of Hurricane Katrina.

\section{Large-Scale Library Disasters}

Other regions have experienced large-scale disasters affecting their libraries, and these episodes provide telling comparisons to Hurricane Katrina. In February 1998, for example, the University of Auckland in New Zealand was forced to close for a week 14

of its 15 libraries when power failed in the city. Only four cables bring power into New Zealand's largest city, and each cable failed in domino-like succession in the weeks leading up to the final blackout on Saturday, February 21. The power failure, which occurred a week before the start of school, forced the university to close, including the university's libraries. The closing of so many campus libraries obviously hampered the majority of the University of Auckland's 24,000 students, a substantial number of whom were returning for the upcoming school term. In addition, access to the library's 
computer network was not available during this time. After the libraries reopened, power was still available only on a limited basis, leaving the buildings with virtually no elevator access, minimal lighting, and no air conditioning (Grant, 2000). At the heart of the problem appeared to be a growing city in a geographically isolated country that was putting an increasing burden on the power supply that ultimately culminated in the power failure.

Disasters affecting an entire library can occur in a relatively narrow path with little or no advance warning and cause incredible damage in a short amount of time. On Saturday, October 30, 2004, torrential rains caused a flash flood that cascaded through the Manoa valley and into Honolulu, Hawaii, on the island of Oahu. The flash flood, which occurred around 8 p.m., devastated the University of Hawaii at Manoa Library, as it carried mud and debris across campus. It was later determined that the floodwaters created a series of powerful nine-foot waves that inundated the ground floor of the library (Davis, 2006). Graduate students attending a library and information science class in the library were forced to break a window to escape the rising floodwaters. Shelves, books, chairs, map cases, and other library materials became a jumbled mess once the floodwaters receded. The library's computer server was destroyed. Over 60,000 maps and 70,000 aerial photographs were damaged and required immediate freezing to avoid a potential mold outbreak. With electrical power out, the library was forced to rely on small generators for months until one large enough to handle the library's electrical needs could be shipped in. The university's proximity to a stream was responsible for the flood and the resultant library damage. 
The Indian Ocean tsunami that occurred on December 26, 2004, is another example of a large-scale disaster that had a significant impact on the region's library community. Caused by a 9.0 earthquake, the enormous tsunami brought unimaginable destruction to Asian countries bordering the Indian Ocean, particularly Sri Lanka. The nation's library sector was devastated. "Nearly 500 schools were affected," reported Sri Lankan librarian Upali Amarasiri (2005), resulting in the loss of approximately 1.2 million volumes of books. In addition, according to Amarasiri, 62 of the country's libraries were damaged, with 28 completely destroyed (pp. 308-309). Other library collections, such as those affiliated with Buddhist temples, were damaged as well.

Another example of libraries being affected by large-scale disasters is the flood that inundated the collections of the Prague Municipal Library and the National Library of the Czech Republic in August, 2002. In this disaster, a heavy rainfall throughout the late summer caused the Vlatva River north of Prague and other nearby rivers to overflow their banks. This flooding not only paralyzed Prague, it caused significant damage to the city's main libraries. In the National Library, the main historical building, the Klementinum, sustained basement flooding to a depth of over three feet $(1 \mathrm{~m})$. While some of the library's collections were damaged, the library's crisis team managed to pump out the water with most books already having been moved to higher floors. A storage facility for this library, however, was in the flood's path and experienced significant damage. Fortunately, about 13,000 volumes were retrieved from the flood waters by the library staff and the Czech Republic army, and afterwards the books were successfully treated. 
The Prague Municipal Library, however, was not so fortunate. The central branch of the library was flooded, though no books were lost. At the Ortenovo Square library facility, the book collection was heavily damaged, including its rare book collection. Enduring five feet $(1.5 \mathrm{~m})$ of flood water, some 30,000 volumes of the library's collection located below the flood line were destroyed. According to Emily Ray (2006), Prague authorities "had assured librarians that the flood would not threaten the Ortenovo Square building, and when it became clear that this was not the case, it was too late to remove the books" (p. 384). The primary causes of the damage to these libraries' collections were the floodwaters and the flawed execution of the library's disaster plans, with some employees unaware of their responsibilities or even absent altogether.

\section{Disaster Plan Effectiveness}

The effectiveness of the disaster plans for each of these libraries during their respective crises varied. In the case of the University of Auckland libraries, they suffered from Auckland's growing dependence upon a limited power source that ultimately resulted in the city-wide outage. Fortunately, in this disaster, the libraries' collections were not threatened, only access to them. The library had an up-to-date "Disaster Preparedness Plan" at the time of the power outage, though details about this plan and how it performed are scant. However, according to an article by Grant (2000), the plan included a list of staff emergency contacts which eased the task of informing the staff of the impending closures. The article also indicated that the disaster drove home the 
importance of advance planning for this type of event, since the area is particularly susceptible to power outages (Grant, 2000).

In the case of the flash flooding at the University of Hawaii at Manoa Library, the disaster appears to have been anticipated. At the time of the flood the library had a disaster plan in place, and the staff quickly responded to salvage what it could. The library's Preservation Department coordinates collection disaster recovery, and its plan is readily available both electronically and in library manuals. In addition, a number of staff has been trained in disaster response techniques. In regard to handling this crisis, Lynn Davis (2006), Head of the Preservation Department, says the disaster, "required ramping up the existing plan, being creative, flexible, and relentless in achieving the goal of stabilizing the collections" (p. 101). The quick action and the library's prioritization of which damaged materials should be saved resulted in the successful salvaging of a significant amount of the affected collection.

The Indian Ocean tsunami affected a large number of Sri Lankan school and public libraries. The libraries that were damaged or destroyed by the tsunami were located along the coast. While several of the major libraries did have disaster plans, there is no literature as to how effective they were during the crisis. However, since the tsunami, Sri Lankan librarians have lobbied for tsunami-resistant library buildings (e.g. those on pillars) as they are rebuilt, new library designs, and the development of special plastic containers in which to store library materials (Amarasiri, 2005). The large-scale disaster 
also illustrated the need for a national library disaster preparedness plan, the creation of which is a priority for that region's library associations.

The damage to Prague's libraries, particularly the National Library, resulted from very wet weather that caused rivers to overflow their banks and enter into the city. The National Library did have disaster plans, which played a significant role in sparing its collections. One thing that hindered the plan's implementation, however, was the library staffs' lack of preparedness. A number of employees did not know what their responsibilities were during the crisis. Indeed, some vital staff members were out of town. These missteps in the execution of the National Library's disaster plan resulted in needless damage to the collections, though ultimately a large number of volumes were saved. Since the disaster, it was implied that aspects that were not addressed in the National Library's emergency preparedness plan prior to the flooding -notably the existence of a contract with a cold storage facility and the availability of emergency supplies—have since been addressed (Ray, 2006).

\section{Common Themes}

Hurricane Katrina and the disasters discussed in the above section all greatly affected libraries. Additionally, while the disasters differed in form, they were all large-scale in scope, affecting widespread areas. When the impact of Hurricane Katrina is considered in light of other large-scale disasters, a number of important themes emerge.

During large-scale disasters, the greatest danger to a library's collection is water. And water damage has many sources, from burst internal plumbing and sewer pipes to 
external acts of nature including rain, hurricanes, flash floods, and tsunamis. All of the Gulf Coast librarians who were contacted reported that the damage caused at their libraries was directly or indirectly related to flood and rain water received during Hurricane Katrina. Similarly, the destruction to libraries and their collections as described at the University of Hawaii at Manoa Library, the Sri Lankan libraries, and the libraries in Prague were all due to exceptionally high rainfall and subsequent flooding. Even the power outage disaster at the University of Auckland libraries did not escape being exacerbated by water. When the power had been restored and the General Library reopened, it was discovered there was a significant sewage blockage involving the library's toilets that resulted in an additional closure of the library.

Clearly, the vulnerability of libraries to water damage is determined in large part by their location. The survey from the Gulf Coast librarians showed the susceptibility of their libraries to flooding. The two respondents from New Orleans reported damage to libraries that were located in the basement and on the first floors of buildings in a city largely at or below sea level. It can be questioned why, in a city at great risk from flooding, the libraries were located in the lowest and most vulnerable part of buildings. Indeed, where one of the libraries was located at a slight elevation, it experienced less flooding. Both respondents from Mississippi reported significant flooding to their libraries, which, again, were located on the first floor of buildings. One of these respondents described the precarious location of not only the building in which the library was located, but the entire research facility. It is located on the shore of Mississippi Sound, with the building housing the library just south of a bayou and marsh. 
Location affected the vulnerability of other libraries discussed. At the University of Hawaii at Manoa, the library is located near Manoa Stream in a valley known for flooding. The libraries damaged or destroyed in Sri Lanka during the Indian Ocean tsunami were located along the coast, the most vulnerable area during a hurricane. The Prague libraries were located close to the Vlatava River.

Large-scale disasters can result in multiple threats to a library's collection, including water damage, mold outbreaks, electrical outages, and damaged technology and equipment. Hurricane Katrina not only brought flooding, it also knocked out electricity in the area, leaving libraries without lights and air conditioning. After the storm passed, many of these libraries that experienced flood damage additionally suffered mold outbreaks due to the high temperatures, humidity, and the lingering presence of flood waters. Thus these libraries had to deal with not just one type of damage, but several occurring at once. The two libraries in Prague also experienced multiple types of damage, including water and mold. Similarly, the Indian Ocean tsunami was strong enough to destroy entire structures as well as flood collections. Here, mold outbreaks also ensued. Obviously, a large-scale disaster causes multiple issues with which a library has to contend. As a result, the potential for damage to library collections is that much greater when libraries are faced with large-scale disasters.

Another theme that emerged from this research is that most disaster plans are designed to mitigate small, localized disasters. In the case of Hurricane Katrina, the existing disaster plans proved ineffectual in responding to a crisis of that magnitude. 
Three of the four librarians responding to the survey indicated the futility of their plans in light of such widespread destruction. The fourth librarian admitted that little disaster preparedness existed at that institution and seemed to despair at a disaster plan being able to address the region's ever-present threat of flooding. Disaster plans were similarly ineffectual during the other disasters examined. At the University of Hawaii at Manoa Library, the plan in place worked well for small disasters. While the existing plan had to be reworked by the staff at the time, it is worth noting that the plan was flexible enough to accommodate the mediation of a larger-scale disaster such as the flash flood that damaged the library's first floor. In the case of the 2004 Indian Ocean tsunami that destroyed many coastal libraries in Sri Lanka, some of the libraries did have disaster plans in place. However, those libraries' disaster plans did not take the threat of tsunamis into account. Even if they had, the disaster was so sudden and devastating, very little, if anything could have been done to preserve the collections.

On the other hand, disaster plans were effective in more localized disasters. For example, at the University of Hawaii at Manoa Library, the existing plan was useful and flexible enough to be able to guide library staff in salvaging priority materials in a short amount of time. Similarly, the disaster plan also worked fairly well during the Prague floods and resulted in protecting the bulk of the collections. It is clear that the disaster plans currently in use can mitigate localized calamities. However, these are small-scale issues when compared to the destruction wrought by Hurricane Katrina or the Indian Ocean tsunami. These examples clearly demonstrate what Preservation Archival Associate Ryan Perry (2006) has also observed: "Disaster plans tend to focus on what an 
organization can do in the case of a disaster of a size that the organization itself can handle" (p. 73).

Finally, for a disaster plan to be effective - even during a large-scale disaster - it must be written down and the staff must be trained in its content and procedures. The staff should be advised on how to prepare the collection before a disaster, when and where to move parts of the collection at risk, which emergency management officials to contact post-disaster for treatment of damaged collection items, and how to contact key library personnel. One of the Gulf Coast librarian respondents from Mississippi indicated very clearly that while the library did have a disaster plan that was utilized for Hurricane Katrina, it was only in a verbal format, which resulted in some problems the Saturday before landfall. At the University of Hawaii at Manoa Library, the plan in place at the time of the flash flood was well-known and readily available, with library staff trained in disaster response. Because of this, the staff responded to the flood quickly and effectively, resulting in the salvage of a large number of damaged items. Despite initial confusion and several missteps, the plan in place at the time of the Prague library floods of 2002 also resulted in a successful salvage operation of those items that were recovered.

\section{Conclusions}

After conducting the research it was discovered that most of the damage to libraries from Hurricane Katrina was the result of flooding from the enormous storm surge. Most survey respondents indicated that there were disaster plans in place, but they were incomplete or ineffectual at mitigating the damage to their libraries and collections. Also, 
there were two noticeable issues discovered that affected the performance of libraries' disaster plans - the location of the library and the scope of the disaster. Similar tales of large-scale disasters affecting international libraries indicated varying levels of effectiveness of their disaster plans that were also based upon the libraries' location and the scope of the calamity. For as comprehensive and well-rehearsed as disaster plans in existence at the time of Hurricane Katrina may have been at any library along the Gulf Coast, they were simply ill-prepared to deal with a calamity of that scope and, thus, could not fully protect a library's collection as vulnerable to flooding as they were. However, the disaster has provided an opportunity for libraries to revise their plans by acknowledging shortcomings related to location and improving the sharing of up-to-date contact information among library personnel before, during, and after a disaster, which will likely have beneficial outcomes for future disasters.

Hurricane Katrina was one of the deadliest and costliest natural disasters ever to strike the United States. The extent of human death, displacement, and overall misery spoke to both the vulnerability of one of the most culturally rich areas of the country and the depths of our nation's inadequate disaster response and recovery capabilities. This is all the more striking when one considers our nation's rapid disaster response internationally compared to the slow and disorganized response in the Gulf Coast region, which still has not fully recovered from the 2005 disaster.

The significance of this research is in highlighting the scenario for libraries after natural forces intersected human ones. Most segments of the Gulf Coast community 
suffered greatly from Hurricane Katrina and the library community was no exception. Many libraries in the region, particularly public libraries, sustained considerable damage. While most have since reopened their doors (some in a new location), many were permanently destroyed. For those libraries that were for the most part spared, Hurricane Katrina and its resultant flooding served as a wake-up call to the importance of rethinking disaster preparedness in the region. This history of the Gulf Coast's collective library community's trials with Hurricane Katrina is an important story that needs to be told. It not only provides an account of what happened, but it also demonstrates that seemingly invulnerable icons like the library can be at risk. The value of this thesis is to illuminate the increased risks libraries in vulnerable areas incur and the need for realistic emergency planning in region such as the Gulf Coast when faced with disasters the magnitude of Hurricane Katrina.

A library's disaster plan can be effective at mitigating damage to a library's collections for a small, localized event. However, chances for its success are diminished when faced with a large-scale disaster, as shown by Hurricane Katrina. The same can be said for those libraries in the path of destruction from a comparable disaster, such as a severe earthquake, a tsunami, or flash flood. As Robert Lipscomb, director of the Harrison County Library system in Mississippi, observed, "The best plan in the world wouldn't have saved this situation; this was completely out of control" (as cited in Clareson \& Long, 2006, p. 38). Simply put, the sheer size and magnitude of Hurricane Katrina and subsequent flooding was too much for any plan to predict or withstand. 
What can be done is for library administrators to keep their personnel as informed as possible about the risks of a disaster that their library may face in the future. Also, communication among library personnel, emergency management officials, and local, state, and federal officials is a necessary precaution for any disaster. Within the library, an up-to-date communication tree so library personnel can be contacted after the disaster is also advised. Finally, in light of the devastation faced by these libraries as a result of Hurricane Katrina, much thought should be given to the future building of libraries in areas of vulnerability like the low-lying areas of the Gulf Coast. 


\section{References}

Alexdi. (Cartographer). (2009). City of New Orleans ground elevations: From Canal St. at the Mississippi River to the lakefront at U.N.O. [Elevation map]. Retrieved from http://en.wikipedia.org/wiki/File:New_Orleans_Elevations.jpg

Amarasiri, U. (2005). Rising from the wreckage: Development of tsunami-affected libraries in Sri Lanka. IFLA Journal, 31(4), 307-314.

Bergman, J. (2008). Disaster: A useful category of historical analysis. History Compass, 6(3), 934-946.

Blake, E. S., Rappaport, E. N., \& Landsea, C. W. (2007). The deadliest, costliest, and most intense United States tropical cyclones from 1851-2006 (and other frequently requested hurricane facts) (NWS TPC-5). Miami, FL: National Weather Service/National Hurricane Center.

Bourne, J. K., Jr. (2004). Gone with the water. National Geographic Magazine, 206(4), 88-105.

Brinkley, D. (2006). The great deluge: Hurricane Katrina, New Orleans, and the Mississippi Gulf Coast. New York, NY: Morrow.

Campanella, R. (2008). Bienville's dilemma: A historical geography of New Orleans. Lafayette, LA: Center for Louisiana Studies.

Clareson, T. \& Long, J. S. (2006). Libraries in the eye of the storm: Lessons learned from Hurricane Katrina. American Libraries, 37(7), 38-41.

Davis, L. A. (2006). Riding the surf: Dealing with library disasters in island communities. Public Library Quarterly, 25(3/4), 99-112. 
Diamond, T. (2006). The impact of Hurricanes Katrina and Rita on three Louisiana academic libraries. Library Administration \& Management, 20(4), 192-200.

Eberhart, G., Flagg, G., Goldberg, B., Goodes, P., Kniffel, L., Landgraf, G., \& Stone, A. (2005). Katrina's terrible toll: Librarians rally to provide information for a devastated Gulf Coast population. American Libraries, 36(9), 14-18, $20-25$.

FEMA. (2004). Hurricane Pam exercise concludes. Retrieved from http://www.fema.gov/news/newsrelease.fema?id=13051

Grant, A. (2000). Benighted! How the university library survived the Auckland power crisis. Australian Academic \& Research Libraries, 31(2), 61-68.

Graumann, A., Houston, T., Lawrimore, J., Levinson, D., Lott, N., McCown, S., . . . Wuertz, D. (2006). Hurricane Katrina: A climatological perspective (2005-01). Asheville, NC: NOAA's National Climatic Data Center. Retrieved from http://www.ncdc.noaa.gov/oa/reports/tech-report-200501z.pdf

Mathews, B. S. (2004). Gray literature: Resources for locating unpublished research. C\&RL News, 65(3). Retrieved from http://www.ala.org/ala/mgrps/divs/acrl/publications/crlnews/2004/mar/graylit.cfm

Huddleston, B. (2007). Two years and counting: New Orleans libraries after Katrina. American Libraries, 38(8), 30-32.

Hurricane Katrina. (n.d.). In Wikipedia. Retrieved October 29, 2009, from http://en.wikipedia.org/wiki/Hurricane_Katrina 
Jumonville, F. M. (2007). I wonder who's using us now: Hurricant [sic] Katrina's influence on use of special collections at the University of New Orleans Library. Southeastern Librarian, 55(3), 8-17.

Kelman, A. (2007). Boundary issues: Clarifying New Orleans's murky edges. Journal of American History, 94(3), 695-703.

LeBoeuf, M.C. (2006). Disasters strike, public libraries prevail: the impact of Hurricanes Katrina and Rita on Louisiana public libraries. Louisiana Libraries, 68(4), 3-7.

Lee, S. (Director, Producer) \& Pollard, S. (Producer). (2006). When the levees broke: A requiem in four acts [Motion picture]. New York, NY: HBO Video.

Levack, K. (2008). By the book: The recovery effort at Tulane University. EContent, 31(5), 16-17.

Mississippi Libraries. (2005). Hurricane Katrina damage: a summary. Mississippi Libraries, 69(4), 93-95.

National Geographic (Producer). (2005). Inside Hurricane Katrina: A comprehensive analysis of the devastation caused by nature's fury [Motion picture]. United States: Warner Home Video.

National Hurricane Center. (2006). Tropical cyclone Report: Hurricane Katrina, 23-30 August 2005. Retrieved from http://www.nhc.noaa.gov/pdf/TCRAL122005_Katrina.pdf

National Oceanic and Atmospheric Administration (NOAA). (2010). The Saffir-Simpson Hurricane Wind Scale. Retrieved from http://www.nhc.noaa.gov/sshws.shtml 
NOVA (Producer). (2005). The storm that drowned a city [Motion picture]. Boston, MA: WGBH Boston Video.

Oder, N. \& Rogers, M. (2005). After Katrina, dismay and recovery: Libraries report the extent of damage as library community continues to mobilize. Library Journal, 130(16), 18-20.

Perry, R. (2006). The great University of Georgia Libraries fire of '03: Lessons learned and questions raised. Public Library Quarterly, 25(3/4), 71-88.

Ray, E. (2006). The Prague library floods of 2002: Crisis and experimentation. Libraries and the Cultural Record, 41(3), 381-391.

Select Bipartisan Committee to Investigate the Preparation for and Response to Hurricane Katrina. (2006). A failure of initiative: Final report of the Select Bipartisan Committee to Investigate the Preparation for and Response to Hurricane Katrina. Washington, D.C.: U.S. Government Printing Office.

Skinner, R. E. (2006). "Nor any drop to drink": New Orleans libraries in the aftermath of Hurricane Katrina. Public Library Quarterly, 25(3-4), 179-187.

The Southern Region Climate Center. (2011). Tropical desk \& hurricanes. Baton Rouge, LA: Louisiana State University. Retrieved from http://www.srcc.lsu.edu/tropdesk/ Van Heerden, I. \& Bryan, M. (2006). The storm: What went wrong and why during Hurricane Katrina: The inside story from one Louisiana scientist. New York, NY: Viking.

Wall, K. L. (2006). Lessons learned from Katrina: What really matters in a disaster. Public Library Quarterly, 25(3/4), 189-198. 


\section{Further Reading}

Atlas. (2009). Atlas: The Louisiana statewide GIS. Retrieved from http://atlas.lsu.edu/

Cave, M. (2008). Through hell and high water: New Orleans, August 29-September 15, 2005. Oral History Review, 35(1), 1-10.

Cole, J. (Author of Screenplay, Producer), Huisenga, S. (Producer), Maiotti, J.

(Producer), Eldridge, M. (Author of Screenplay), and Carroll, M. (Narrator). (2006).

Inside Hurricane Katrina [Motion picture]. United States: Warner Home Video.

Curzon, S. C. (2000). When disaster strikes: The fall and rise of a library. American Libraries, 31(4), 64-69.

Curzon, S. C. (2006). Coming back from major disaster: Month one.

Public Library Quarterly, 25(3/4), 17-29.

Daniels, R. J., Kettl, D. F., Kunreuther, H., \& Gutmann, A. (2006). On risk and disaster: Lessons from Hurricane Katrina. Philadelphia, PA: University of Pennsylvania Press.

Doolittle, E. M. (2007). Katrina: The storm - the aftermath. Southeastern Librarian, $55(3), 4-7$.

Doolittle, E. M. (2007). Visibility and direct contact: A library moves forward. Mississippi Libraries, 71(4), 93-95.

Dudenhoffer, C. (2007). Keeping the beast at bay: Fighting mold at the University of Missouri-Columbia Journalism Library. Public Library Quarterly, 25(3), 143-150. 
Ellis, J. (2007). Lessons learned: The recovery of a research collection after Hurricane Katrina. Collection Building, 26(4), 108-111.

Ellis, J. B. \& Shambra, J. (2008). Reshaping public services after a disaster. Mississippi Libraries, 72(3), 51-53.

FEMA. (2009). Hurricane Katrina page. Retrieved from http://www.fema.gov/hazard/flood/recoverydata/katrina/

Gugliotta, T. (2006). Fire at University of New Mexico Library. Public Library Quarterly, 25(3/4), 61-69.

Kennedy, T. D. (2006). Steamy situation: Water emergency in Sterling Memorial Library. Public Library Quarterly, 25(3/4), 89-97.

Kettl, D. F. (2006). Is the worst yet to come? [Electronic version]. The ANNALS of the American Academy of Political \& Social Science, 604, 273-287.

Leonov, V. (2004). Fire recovery and preservation of collections at the Russian Academy of Sciences Library. Advances in Librarianship, 27(2004), 199-218.

Louisiana State University. (2009). Hurricane Katrina \& Rita clearinghouse cooperative. Retrieved from http://katrina.lsu.edu/default.asp

MARIS. (2009). Mississippi automated resource information system. Retrieved from http://www.maris.state.ms.us/

National Oceanic and Atmospheric Administration (NOAA). (2007). Hurricane Katrinamost destructive hurricane ever to strike the U.S. Retrieved from http://www.katrina.noaa.gov/ 
Olle-Jajoie, M. (2007). Hurricane Katrina. DttP: A Quarterly

Journal of Government Information Practice \& Perspective, 35(3), 35-36.

Pinhong, S. \& Shitian, L. (2006). The urgent need to preserve and conserve ancient books: From the event that ancient books collected in Yongquan Monastery were damaged by a flood: Case study. International Preservation News, 38, 15-21.

Polastron, L. X. (2007). Books on fire: The destruction of libraries throughout history. Rochester, VT: Inner Traditions.

Rodrigues, L.L. \& Craig, R. (2008). Recovery amid destruction: Manoel da Maya and the Lisbon Earthquake of 1755. Libraries and the Cultural Record, 43(4), 397-410.

Silverman, R. (2006). Toward a national disaster response protocol. Libraries \& the Cultural Record, 41(4), 497-511.

Smith, S. B. (2006). Observations of ground zero: From the outside. Public Library Quarterly, 25(3/4), 151-157.

Strudwick, J. (2006). A selected bibliography of library disaster stories: Before, during, and after. Public Library Quarterly, 25(3/4), 7-16.

Tadman, A. (2006). Reflections on Ochsner Medical Library: A year after the storm. Louisiana Libraries, 69(2), 3-5. 
Appendix A-Survey Form Sent to Select Gulf Coast Librarians

\section{Questionnaire on the Impact of Hurricane Katrina on Gulf Coast Libraries}

\section{NAME OF PARTICIPANT: \\ INSTITUTION NAME: \\ PROFESSIONAL TITLE:}

1. Generally speaking, what types of damage did your library/archives sustain during and after Hurricane Katrina?

2. What was the total dollar amount of disaster-related casualty losses to the building, contents, and collections? Please provide a breakdown of the losses if available.

3. Where was damage to your institution the heaviest (i.e., basement holdings, first floor, exterior structure, etc.)? Please be specific.

4. Were there pre-existing factors that contributed to the level and nature of damage to your facility and/or collections? If so, please elaborate.

5. What was the disaster plan you had in place for your library/archives prior to Hurricane Katrina? Were any drills or mock disasters ever conducted? Please elaborate and include any written policy.

6. What parts of the disaster plan worked and what parts need revision? Can you explain why or why not?

7. What is your current disaster preparedness policy? Can you expand on how this policy differs from what may have existed pre-Katrina?

8. How has Hurricane Katrina impacted the rebuilding of your facility and collections/archives? How has it affected the employee-patron relationship? 


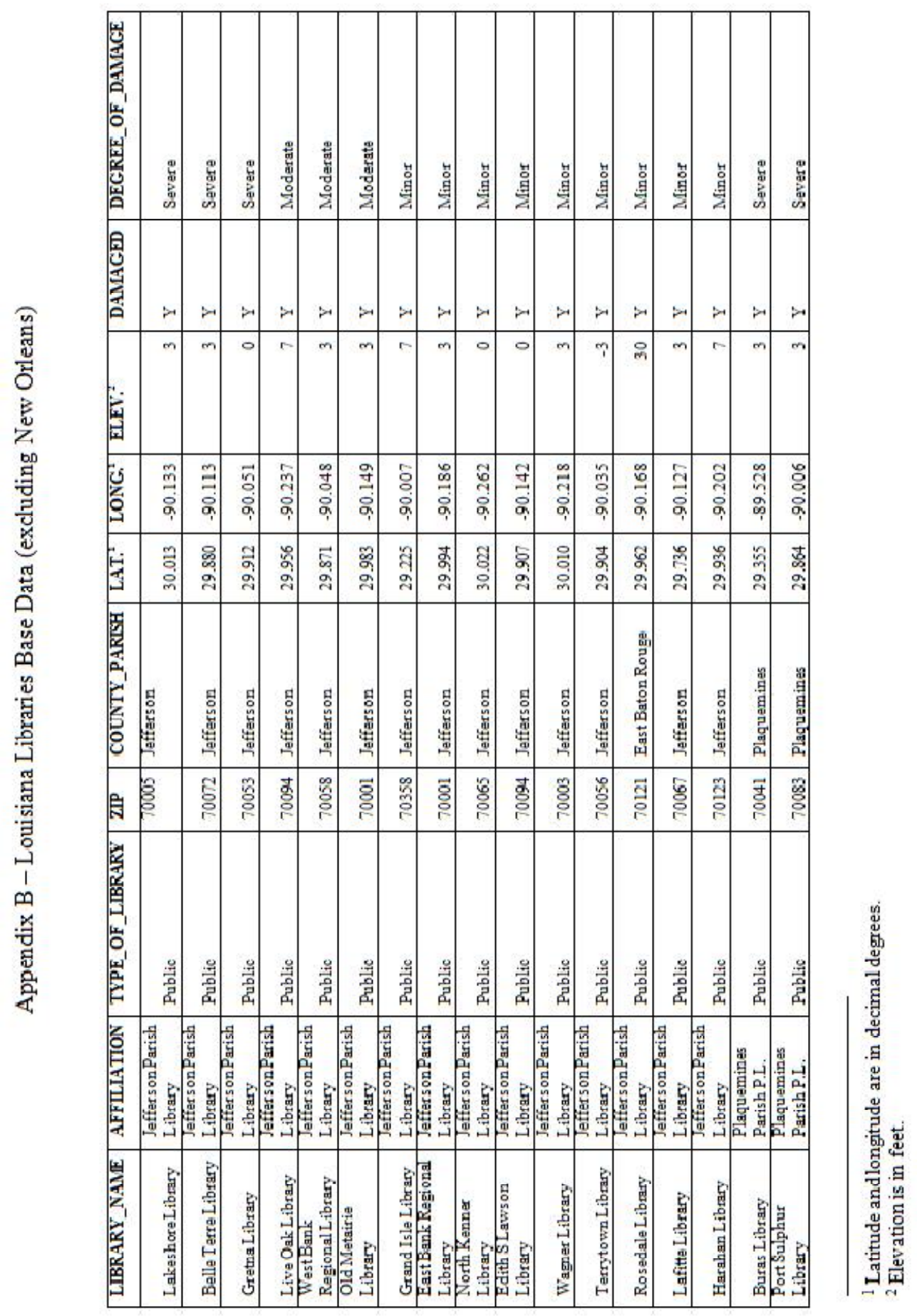




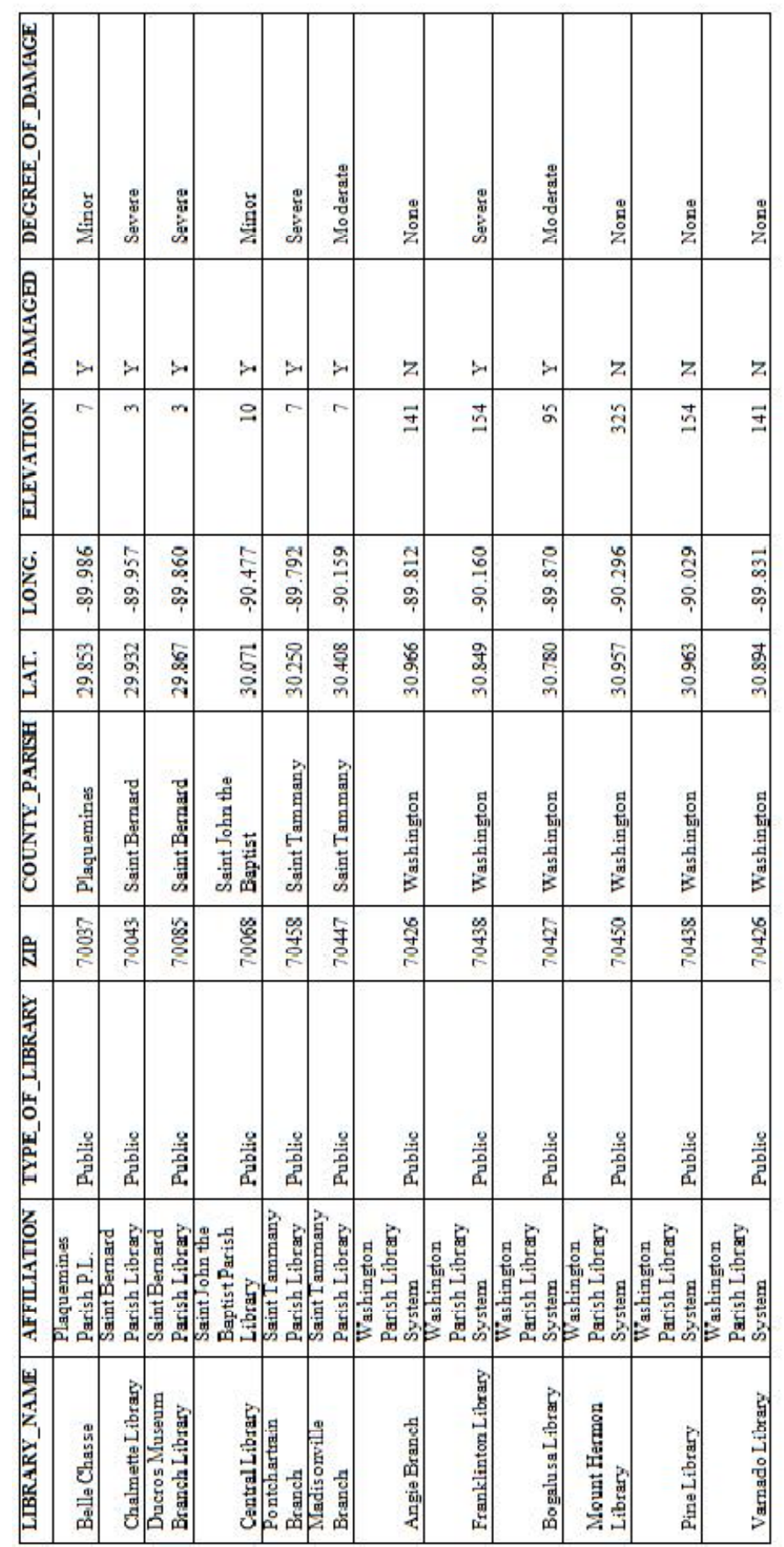




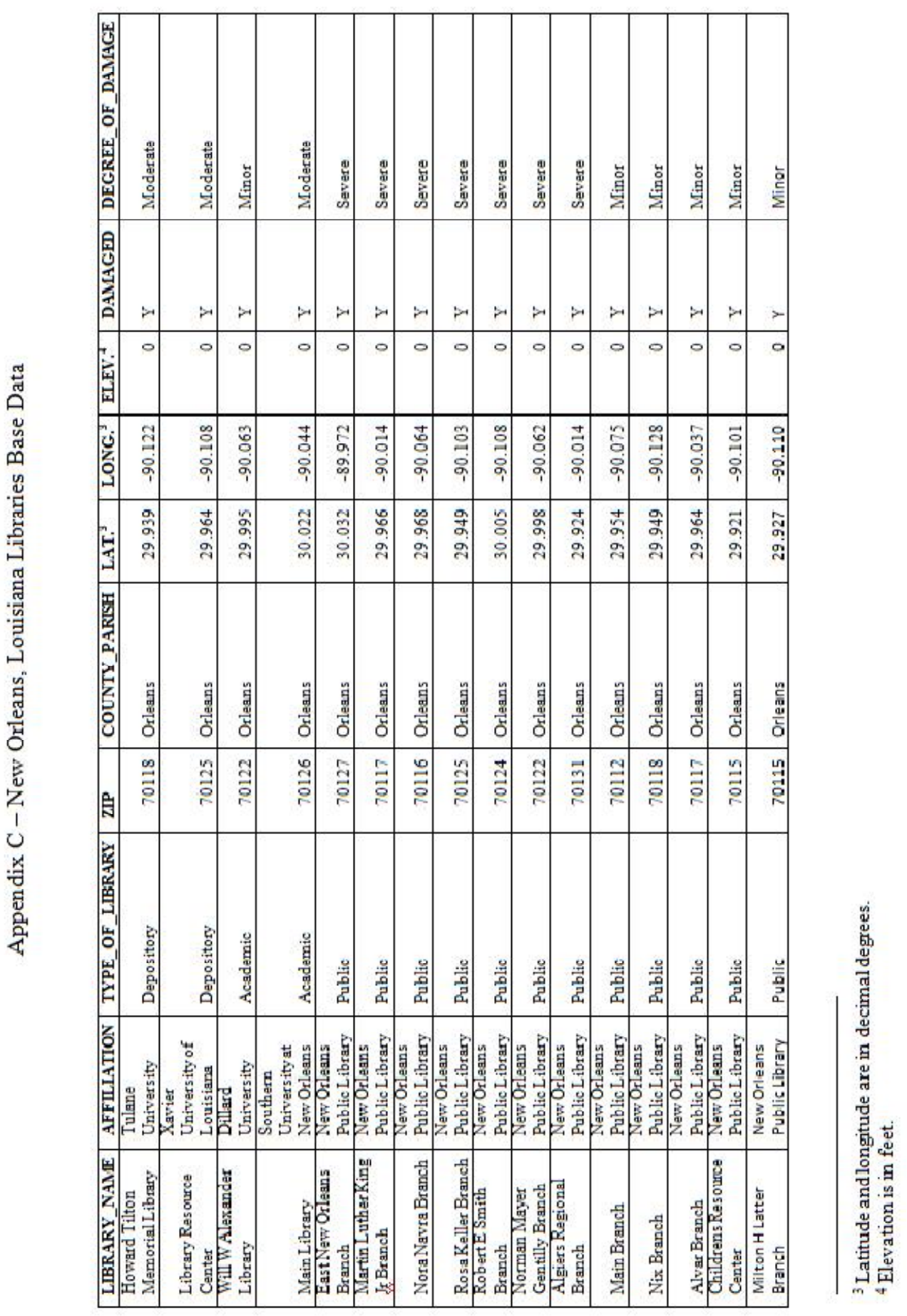




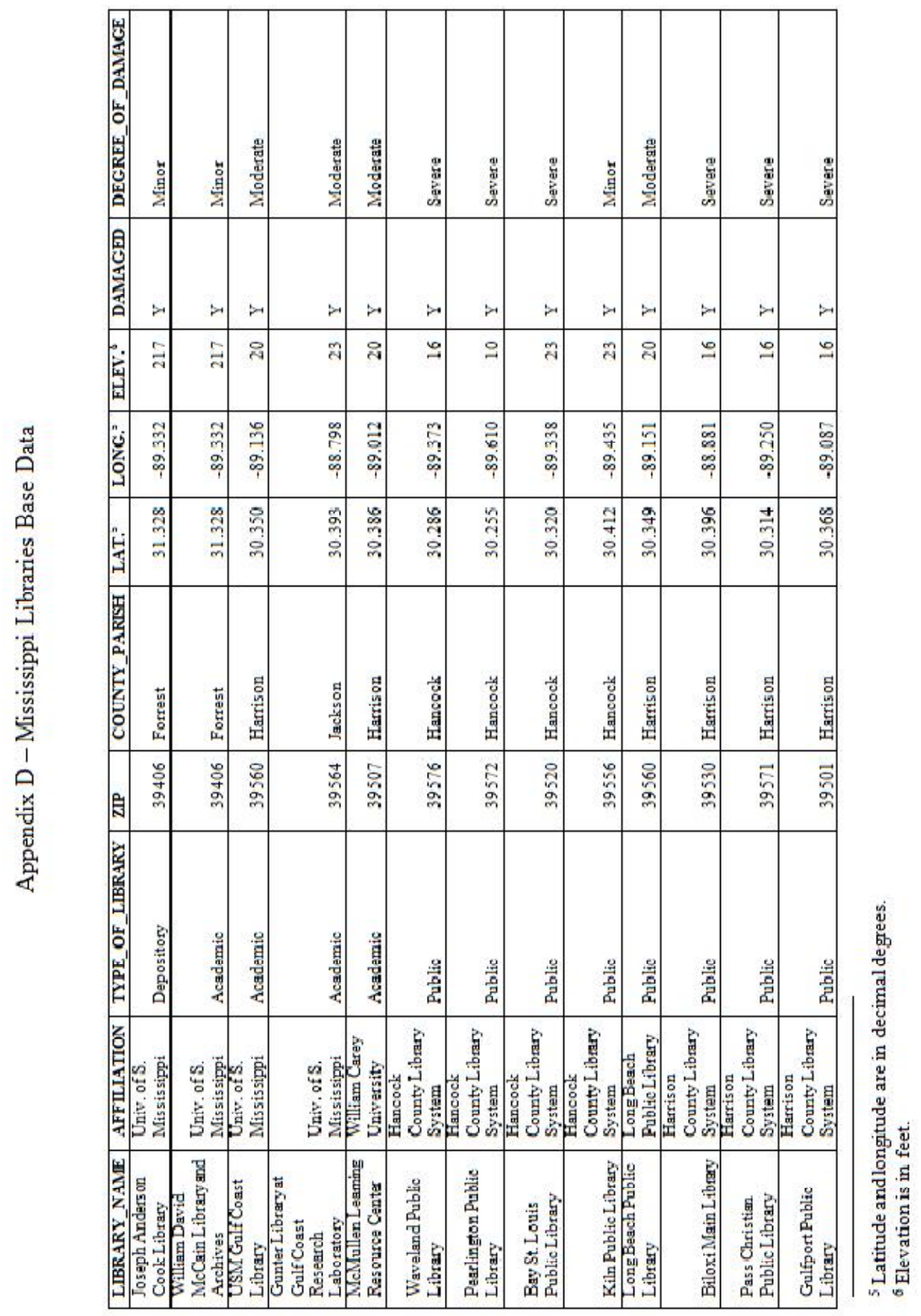




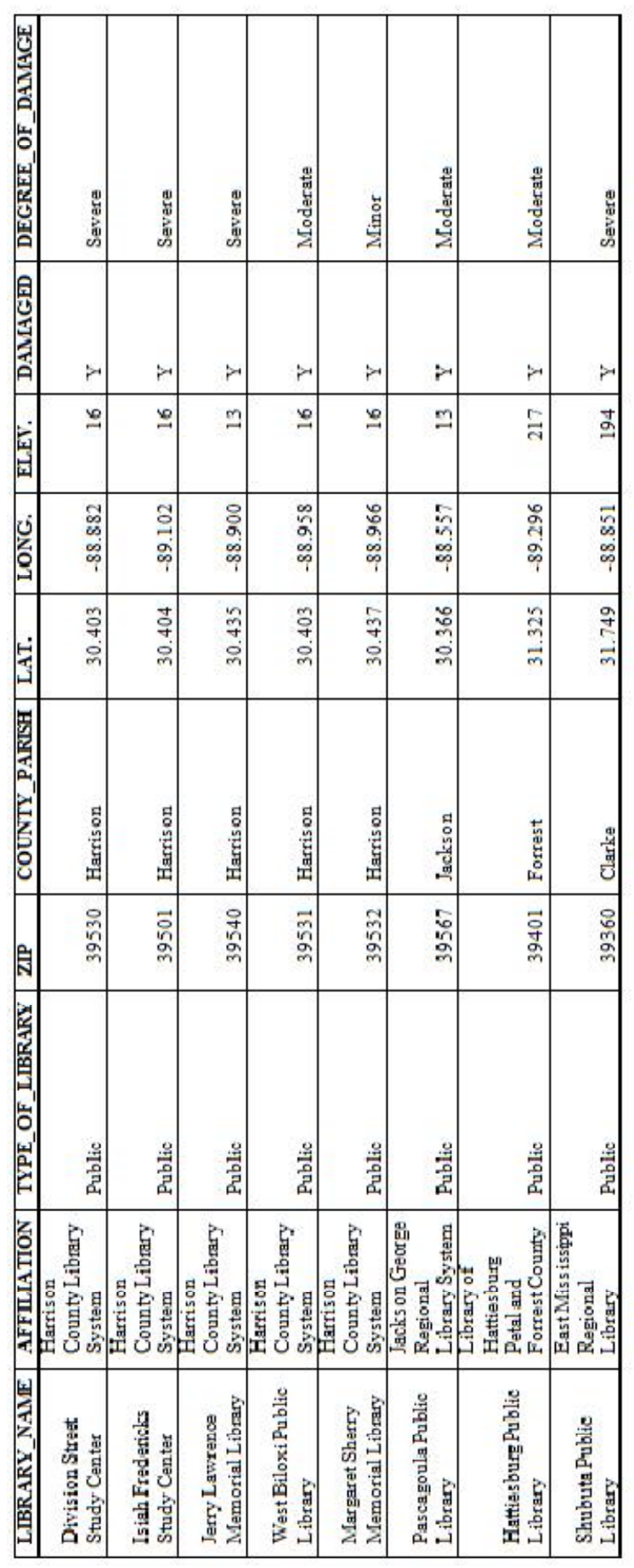

